\title{
Confining iron oxide nanocubes inside submicrometric cavities as a key strategy to preserve magnetic heat losses in an intracellular environment
}

Mikhail V. Zyuzin ${ }^{1,2}$, Marco Cassani ${ }^{1,3}$, Markus J. Barthel ${ }^{1}$, Helena Gavilan ${ }^{1}$, Niccolò Silvestri ${ }^{1,3}$, Alberto Escudero $^{4,5}$, Alice Scarpellini ${ }^{1}$, Federica Lucchesi ${ }^{1,6}$, Francisco J. Teran $^{7,8}$, Wolfgang J. Parak ${ }^{9 *}$, Teresa Pellegrino ${ }^{1^{*}}$.

1. Istituto Italiano di Tecnologia, Via Morego 30, 16163 Genova, Italy.

2. Faculty of Physics and Engineering, ITMO University, Lomonosova 9, 191023 St. Petersburg, Russia

3. Dipartimento di Chimica, Università di Genova , Via Dodecaneso 33, 16146 Genova, Italy

4. Leibniz Institute for New Materials. Campus D2 2. D-66123 Saarbrücken, Germany

5. Departamento de Química Inorgánica and Instituto de Investigaciones Químicas (IIQ), Universidad de Sevilla - CSIC, Calle Américo Vespucio 49, E-41092 Seville, Spain.

6. Dipartimento di Informatica, Bioingegneria, Robotica e Ingegneria dei Sistemi (DIBRIS), Via all'Opera Pia, 13, 16145, Genova

7. iMdea Nanociencia, Campus Universitario de Cantoblanco, 28049 Madrid, Spain

8. Nanobiotecnología (iMdea-Nanociencia), Unidad Asociada al Centro Nacional de Biotecnología (CSIC), 28049 Madrid, Spain

9. Faculty of Physics and Chemistry and CHyN, Universität Hamburg, 20146, Hamburg, Germany

\footnotetext{
* corresponding authors: wolfgang.parak@uni-hamburg.de and teresa.pellegrino@iit
} 

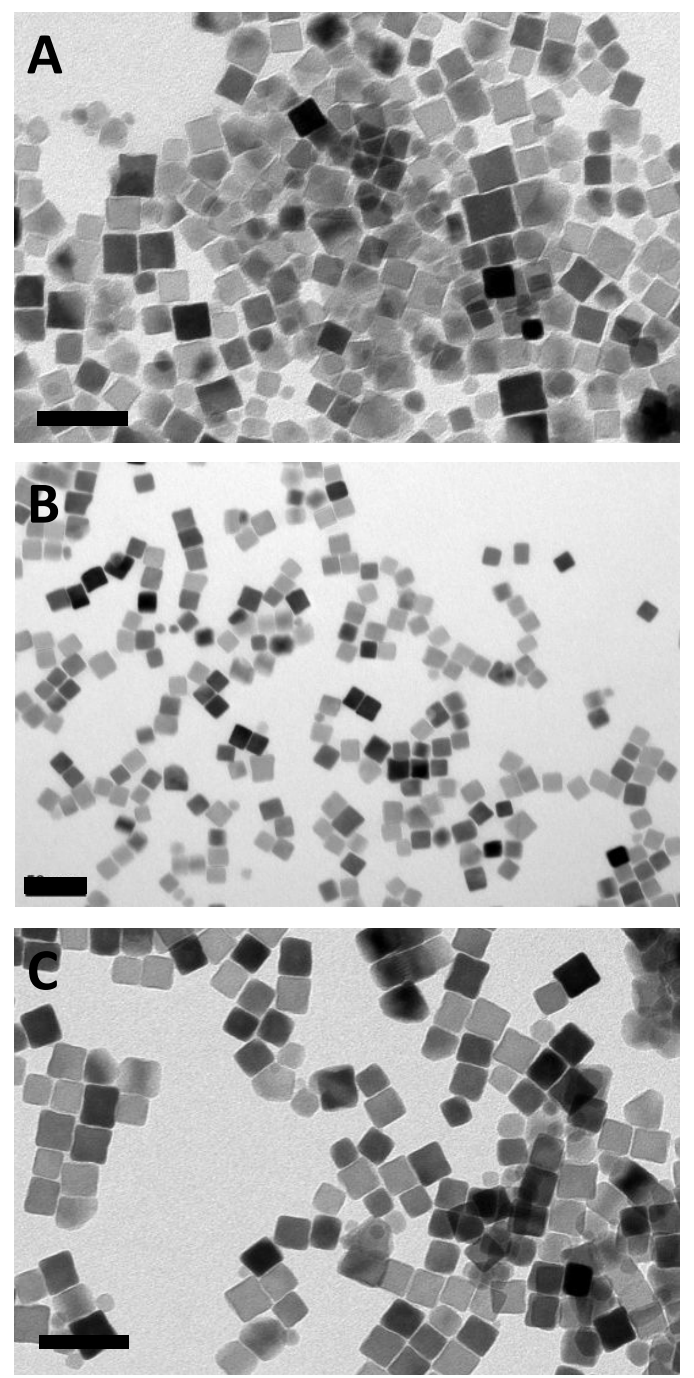

Figure S1: Transmission electron images of the pristine cubic iron oxide nanoparticles (IONCs; A: $14 \mathrm{~nm}$, B: 16 $\mathrm{nm}$ and C: $18 \mathrm{~nm}$ edge size) as deposited from chloroform before the water transfer procedure. Scale bars correspond to $50 \mathrm{~nm}$. Water phase transfer results in narrower size distribution of IONCs because of multiple centrifugation steps, which sort out tiny non-cubic particles. 


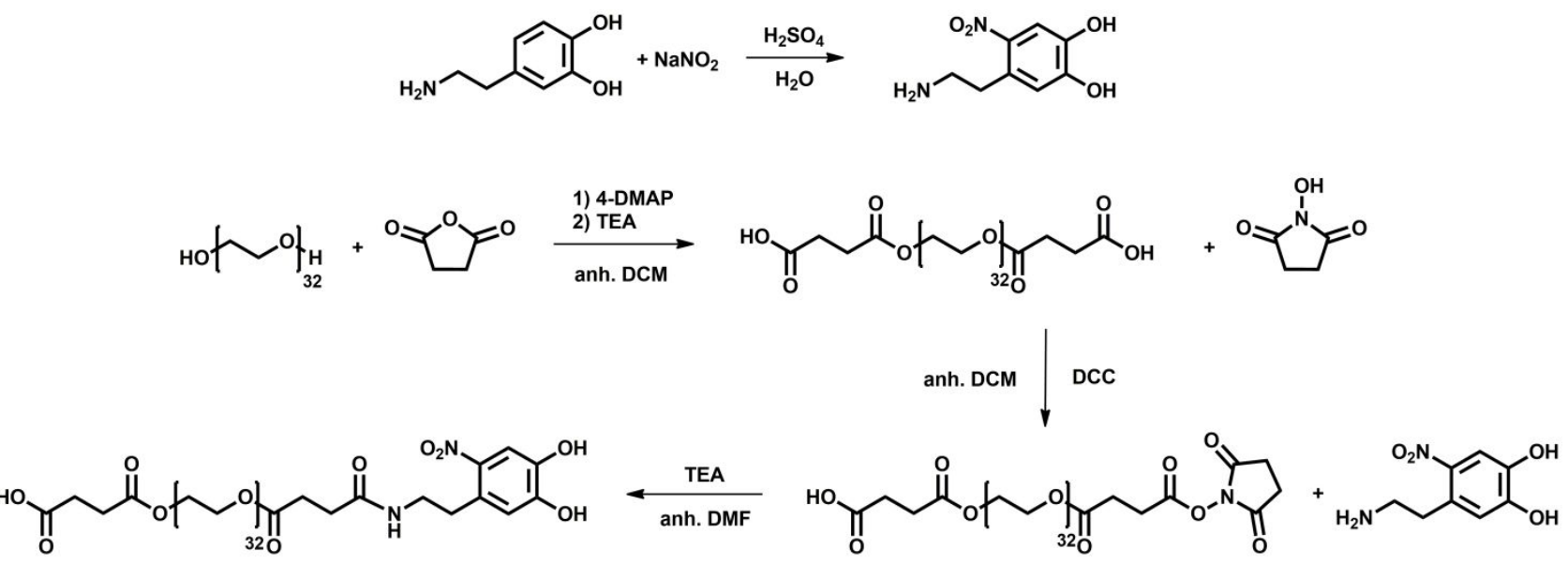

Scheme S1: Multi-step approach for the preparation of the chatecol-PEG.-carboxylic terminated ligand used for the water transfer protocol.

\section{Synthesis of nitrodopamine (ND)}

The synthesis of nitrodopamine (ND) was adopted from literature. ${ }^{1}$ In a two-neck round bottom flask $3.8 \mathrm{~g}$ dopamine hydrochloride $(20 \mathrm{mmol})$ and $3.04 \mathrm{~g}$ sodium nitrite $(44 \mathrm{mmol})$ were dissolved in $50 \mathrm{~mL}$ MilliQ water and cooled down to $5^{\circ} \mathrm{C}$ using an ice-bath. $1.96 \mathrm{~mL}$ (34.8 mmol) sulfuric acid dissolved in $20 \mathrm{~mL}$ MilliQ water were filled in a dropping funnel and connected to the reaction vessel. The acid was added slowly and dropwise to the reaction mixture under vigorous stirring. Afterwards, approximately $10 \mathrm{~mL}$ acid addition the product precipitated as yellowish solid blocking the magnetic stirring. Therefore, additional $20 \mathrm{~mL}$ of MilliQ water were added and the remaining sulfuric acid was added. The mixture was vigorously stirred at RT overnight at RT. Subsequently, the product was filtered off and re-crystallized from water. The pure product was observed as dark brownish needles in the hemisulfate form.

${ }^{1} \mathrm{H}$ NMR (400 MHz, $\left.\mathrm{D}_{2} \mathrm{O}, \delta(\mathrm{ppm})\right): 7.63\left(\mathrm{~s}, 1 \mathrm{H}, \mathrm{CH}\right.$ arom.), 6.82 (s, $1 \mathrm{H}, \mathrm{CH}$ arom.), 3.24 (t, $2 \mathrm{H},-\mathrm{CH}_{-}-\mathrm{CH}_{2}-\mathrm{CH}_{2}-$ $\mathrm{COOH}), 3.13\left(\mathrm{t}, 2 \mathrm{H},-\mathrm{CH}-\mathrm{CH}_{2}-\mathrm{CH}_{2}-\mathrm{COOH}\right)$.

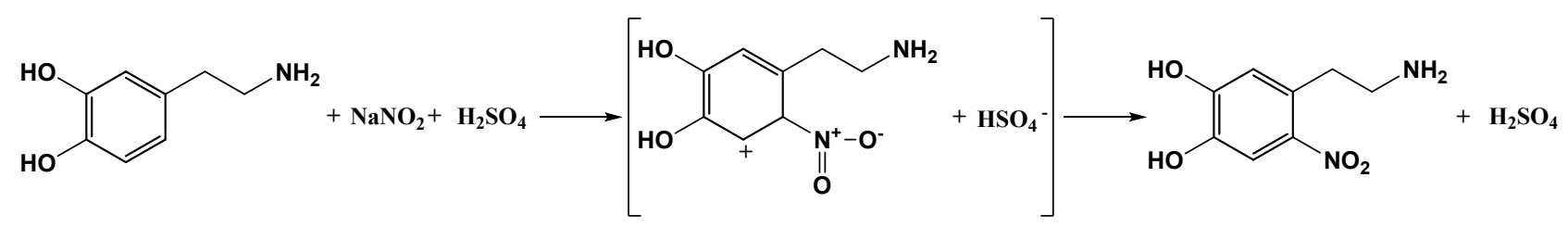

Scheme S2: Schematic representation of the synthesis of nitrodopamine obtained as hemisulfate salt. 


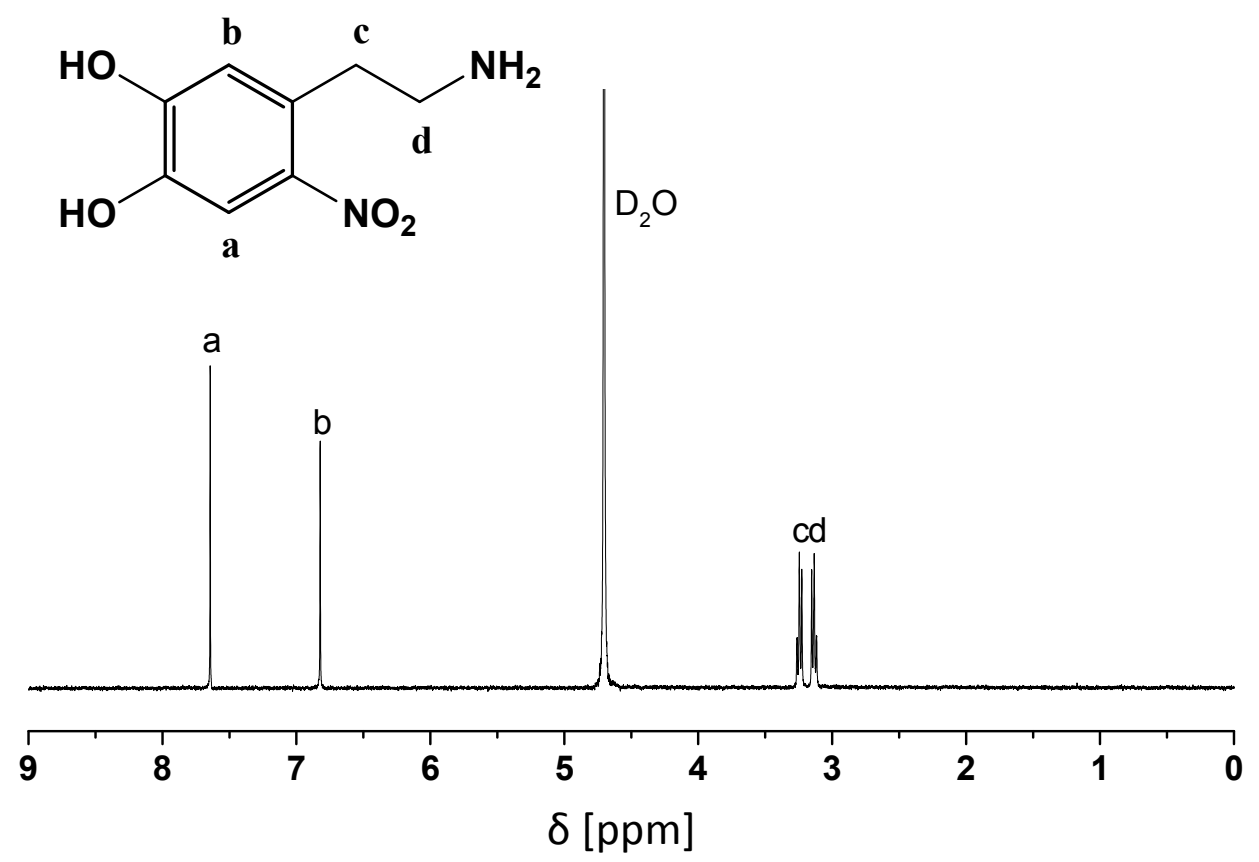

Figure S2: ${ }^{1} H$ NMR spectrum of nitrodopamine (solvent: $D_{2} O$ ).

\section{Synthesis of $\alpha$ - $\omega$-carboxy-poly(ethylene glycol) (COOH-PEG-COOH)}

$16 \mathrm{~g}$ (11.43 mmol, $22.86 \mathrm{mmol} \mathrm{OH}$ groups) of $\alpha$ - $\omega$-hydroxypoly(ethylene glycol) were dried in a two-neck flask under vacuum and heated to $70^{\circ} \mathrm{C}$ for $2 \mathrm{~h}$. Afterwards, the reaction vessel was set under nitrogen atmosphere and the PEG precursor was dissolved in $150 \mathrm{~mL}$ anhydrous dichloromethane. Subsequently, 0.6 $\mathrm{mL}$ triethylamine ( $4.34 \mathrm{mmol}), 160 \mathrm{mg}$ 4-dimethylaminopyridine $(1.18 \mathrm{mmol})$, and $2.87 \mathrm{~g}$ succinic anhydride $(28.67 \mathrm{mmol}$ ) were added to the mixture under nitrogen and vigorous stirring. The solution was stirred overnight at RT, washed 3 times with water using a separation funnel, and concentrated using a rotary evaporator. The pure product was obtained via precipitation in ice-cold diethyl ether, filtration and drying under vacuum. ${ }^{1} \mathrm{H}$ NMR (400 MHz, DMSO, $\left.\delta(\mathrm{ppm})\right): 4.12\left(\mathrm{t}, 4 \mathrm{H}, \mathrm{OOC}-\mathrm{CH}_{2}-\mathrm{CH}_{2}-\mathrm{O}\right), 3.60\left(\mathrm{t}, 4 \mathrm{H}, \mathrm{OOC}-\mathrm{CH}_{2}-\mathrm{CH}_{2}-\mathrm{O}\right), 3.5$ (broad,PEG). $f=97 \%$
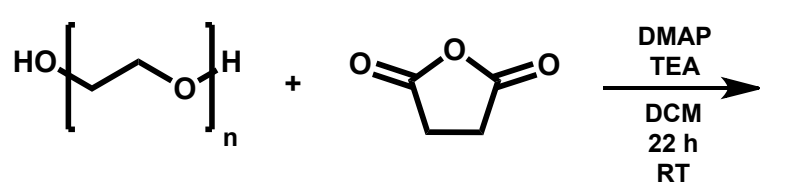<smiles>CC(C)(COC(=O)CCC(=O)O)OC(=O)CCC(=O)O</smiles>

Scheme S3: Schematic representation of the synthesis of $\alpha$ - $\omega$-carboxy poly(ethylene glycol). 


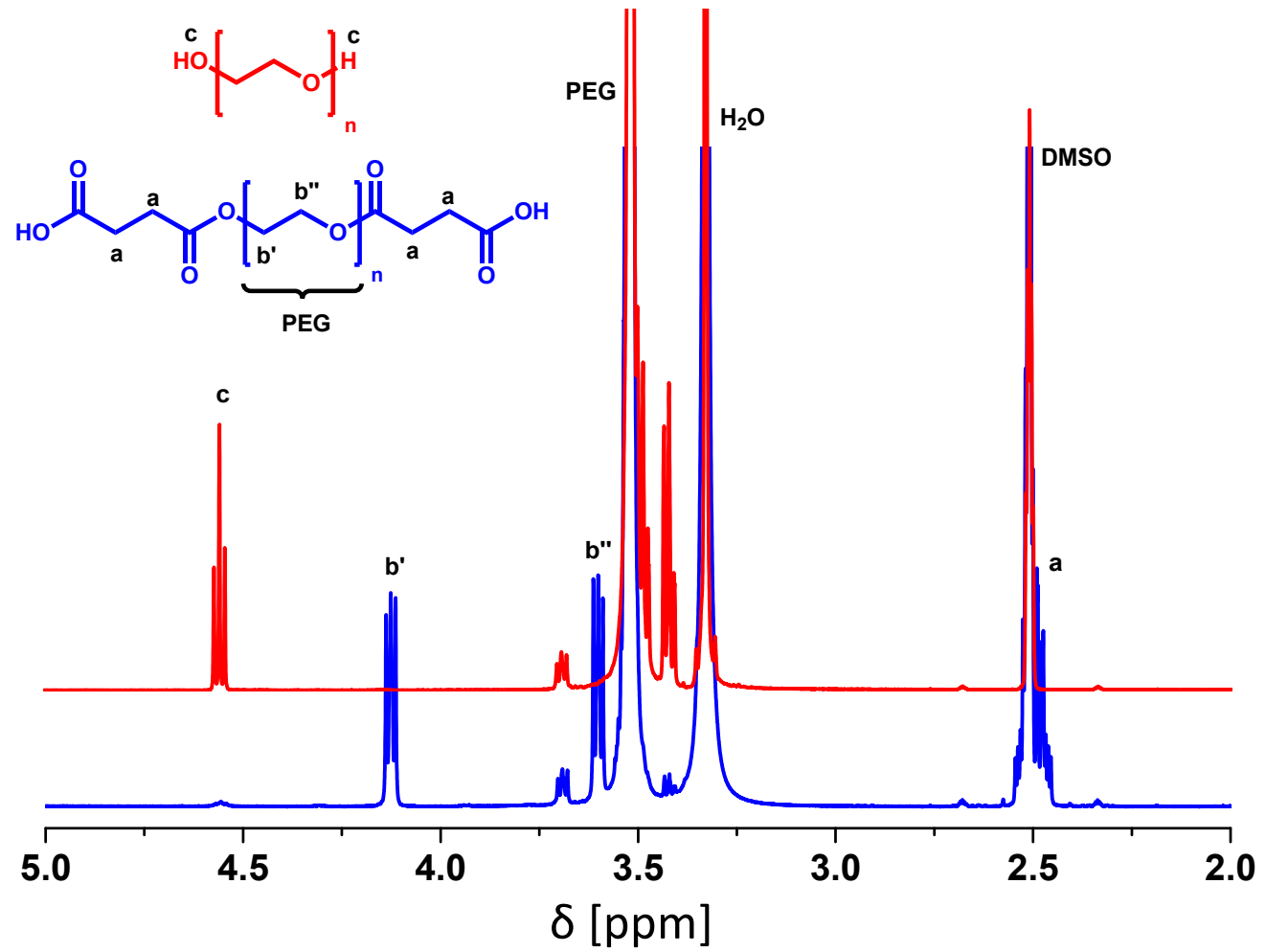

Figure S3: ${ }^{1} H$ NMR spectra of the initial $\alpha$ - $\omega$-hydroxypoly (ethylene glycol) and final $\alpha$ - $\omega$-carboxy poly(ethylene glycol) (solvent:DMSO-d6).

\section{Synthesis of $\alpha-N$-hydroxysuccinimide- $\omega$-carboxypoly(ethylene glycol) (NHS-PEG-COOH)}

For the activation of one carboxy group with $N$-hydroxysuccinimide a literature protocol was used with minor modifications. ${ }^{2}$ In a two-neck flask $3 \mathrm{~g}(2.14 \mathrm{mmol}, 4.28 \mathrm{mmol} \mathrm{COOH}$ groups) of $\alpha$ - $\omega$-carboxy-poly(ethylene glycol) were dried under vacuum at $70^{\circ} \mathrm{C}$ for $2 \mathrm{~h}$. After cooling to RT, $45 \mathrm{~mL}$ of anhydrous dichloromethane were added under nitrogen atmosphere to dissolve the polymeric precursor and $271 \mathrm{mg} \mathrm{N}$ hydroxysuccinimide (2.36 mmol, 1.1 eq.) were added under vigorous stirring. Subsequently, $584 \mathrm{mg} \mathrm{N,N^{ \prime } -}$ dicyclohexylcarbodiimide (DDC, $2.83 \mathrm{mmol}, 1.2 \mathrm{eq}$.) were dissolved in $15 \mathrm{~mL}$ anhydrous dichloromethane and added slowly to the mixture with a syringe. The mixture was allowed to stir over-night at RT, resulting in the precipitation of the reacted DDC. The solution was filtered using a paper filter to remove the precipitate, the organic phase was washed two times with water, and the product was obtained by precipitation in ice-cold diethyl ether. The final product was filtered and dried under vacuum.

${ }^{1} \mathrm{H}$ NMR (400 MHz, DMSO, $\left.\delta(\mathrm{ppm})\right): 4.15\left(\mathrm{t}, 4 \mathrm{H}, \mathrm{OOC}-\mathrm{CH}_{2}-\mathrm{CH}_{2}-\mathrm{O}\right.$ ), 3.60 (t, $4 \mathrm{H}, \mathrm{OOC}-\mathrm{CH}_{2}-\mathrm{CH}_{2}-\mathrm{O}$ ), 3.51 (broad, PEG), 2.91 (t, $2 \mathrm{H}, \mathrm{OOC}-\mathrm{CH}_{2}-\mathrm{CH}_{2}-\mathrm{CON}$ ), $2.81\left(\mathrm{~s}, 4 \mathrm{H}, \mathrm{NOC}-\mathrm{CH}_{2}-\mathrm{CH}_{2}-\mathrm{CON}\right), 2.70\left(\mathrm{t}, 2 \mathrm{H}, \mathrm{OOC}-\mathrm{CH}_{2}-\mathrm{CH}_{2}-\mathrm{CON}\right) \cdot f=$ $55 \%$ 


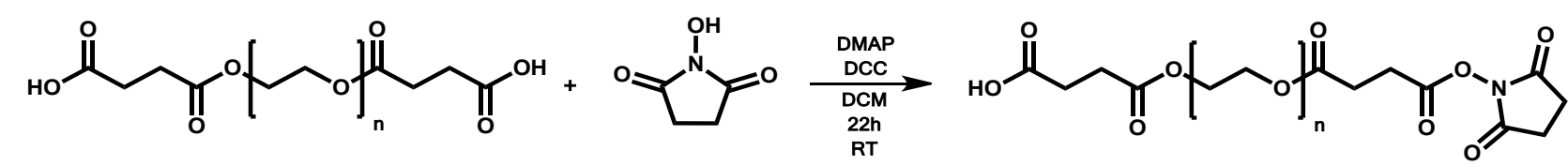

Scheme S4: Schematic representation of the synthesis of $\alpha$-N-hydroxysuccinimide- $\omega$-carboxypoly(ethylene glycol).

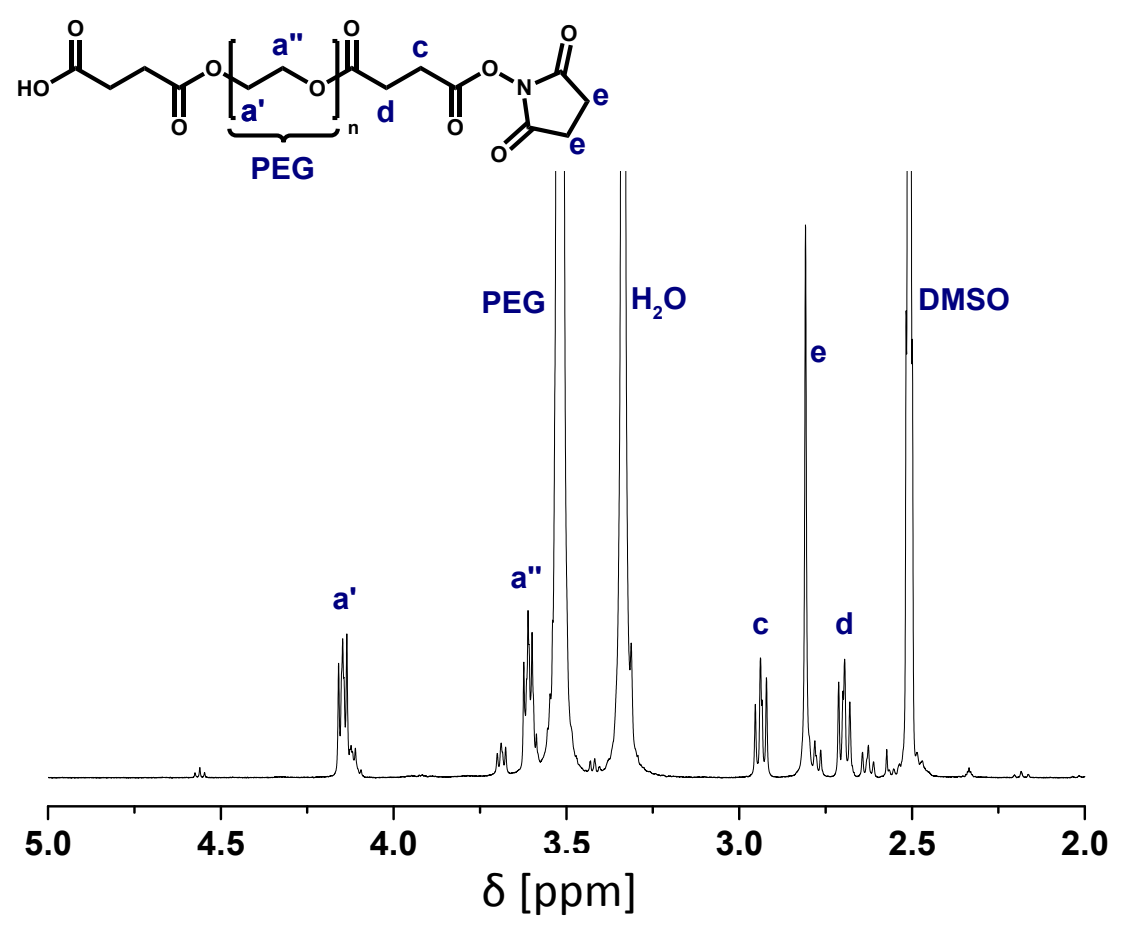

Figure S4: ${ }^{1} H$ NMR spectrum of $\alpha$-N-hydroxysuccinimide- $\omega$-carboxypoly(ethylene glycol) (solvent:DMSO-d6).

\section{Synthesis of $\alpha$-nitrodopamine- $\omega$-carboxy-poly(ethylene glycol) (ND-PEG-COOH)}

For the coupling of nitrodopamine a literature protocol was used with minor modifications. ${ }^{2}$ In a two-neck flask $2.1 \mathrm{~g}$ (1.5 mmol) $\alpha$ - $N$-hydroxysuccinimide- $\omega$-carboxy-poly(ethylene glycol) were dried under vacuum at $70{ }^{\circ} \mathrm{C}$. Afterwards, $75 \mathrm{~mL}$ of dimethylformamide were added to dissolve the polymeric precursor. Subsequently, $370 \mathrm{mg}$ ( $1.5 \mathrm{mmol}, 1$ eq.) nitrodopamine in the hemisulfate form and $1.03 \mathrm{~mL}(7.5 \mathrm{mmol}, 5$ eq.) of triethylamine were added and the mixture was allowed to stir in the dark over-night. Dimethylformamide was removed using a rotary evaporator and the solid residue was re-dissolved in dichloromethane. The organic phase was washed 2 times with acidic water $(\mathrm{pH} 2-3)$, concentrated using a rotary evaporator, and the product was precipitated in ice-cold diethyl ether. The final product was obtained by filtration and drying under vacuum.

${ }^{1} \mathrm{H}$ NMR (400 MHz, DMSO, $\left.\delta(\mathrm{ppm})\right): 7.97$ (1 H, OC-NH-CH 2 ), 7.48 (s, 1H, CHarom.),6.69 (s, 1H, CHarom.), 4.11 (t, $4 \mathrm{H}, \mathrm{OOC}-\mathrm{CH}_{2}-\mathrm{CH}_{2}-\mathrm{O}$ ), 3.60 (t, $4 \mathrm{H}, \mathrm{OOC}-\mathrm{CH}_{2}-\mathrm{CH}_{2}-\mathrm{O}$ ), 3.52 (broad, PEG), 2.88 (t, $2 \mathrm{H}, \mathrm{C}-\mathrm{CH}_{2}-\mathrm{CH}_{2}-\mathrm{COO}$ ), 2.33 $\left(\mathrm{t}, 2 \mathrm{H}, \mathrm{OC}-\mathrm{CH}_{2}-\mathrm{CH}_{2}-\mathrm{COO}\right) \cdot f=60 \%$ 


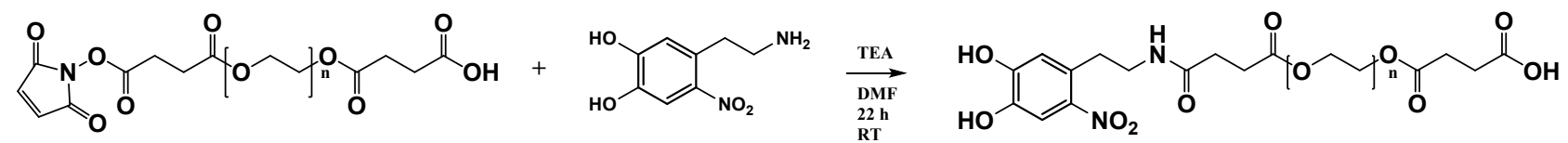

Scheme S5: Schematic representation of the synthesis of $\alpha$-nitrodopamine- $\omega$-carboxypoly(ethylene glycol).

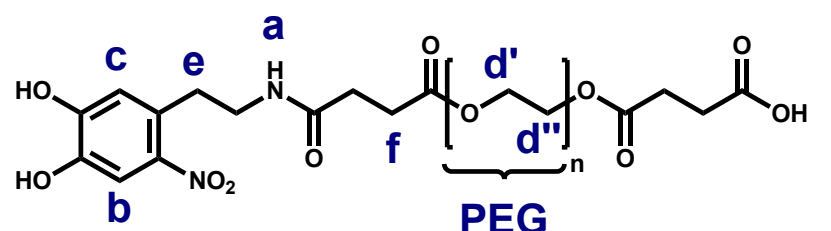

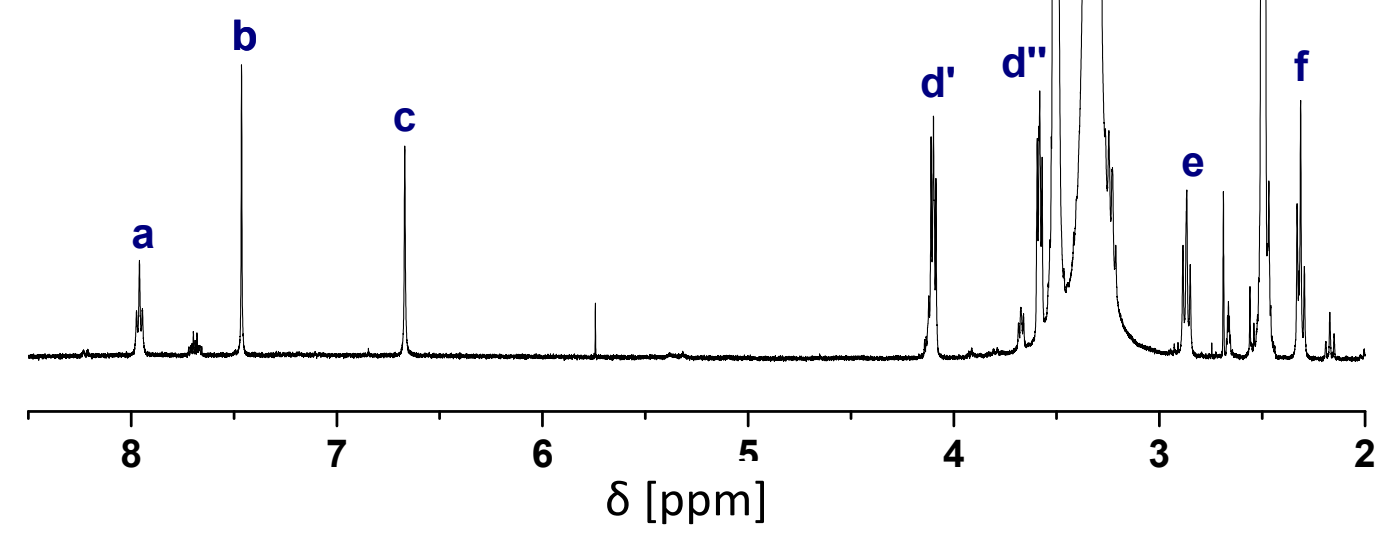

Figure S5: ${ }^{1}$ H NMR spectrumof $\alpha$-nitrodopamine- $\omega$-carboxypoly(ethylene glycol) (solvent:DMSO).

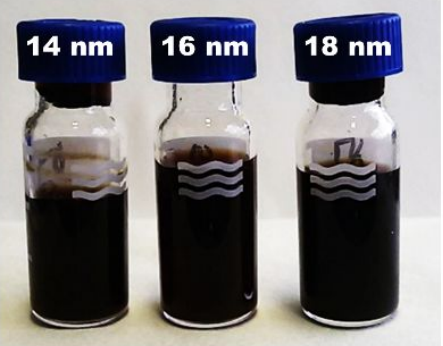

Figure S6: Photograph of the obtained IONCs after transfer to water with edge sizes of 14,16 and, $18 \mathrm{~nm}$ (from the left to right). 
Table S1: Hydrodynamic diameters $\left(D_{h}\right)$ measured by DLS in aqueous solutions of IONCS of 14-18 $\mathrm{nm}$, and the corresponding DLS characterization of CAPS and WALL samples and $\zeta$-Potential.

\begin{tabular}{|c|c|c|c|c|}
\hline SAMPLE & $\mathrm{D}_{\mathrm{h}}$ (Intensity) [nm] & $\mathrm{D}_{\mathrm{h}}$ (Volume) [nm] & $D_{h}$ (Number) [nm] & క-Potential [mV] \\
\hline IONCs $-14 \mathrm{~nm}$ & $41 \pm 22$ & $21 \pm 9$ & $15 \pm 6$ & $-24 \pm 2$ \\
\hline IONCs - $16 \mathrm{~nm}$ & $48 \pm 28$ & $35 \pm 12$ & $25 \pm 7$ & $-33 \pm 3$ \\
\hline IONCs $-18 \mathrm{~nm}$ & $93 \pm 34$ & $75 \pm 15$ & $39 \pm 7$ & $-26 \pm 2$ \\
\hline CAPS - IONCs - $14 \mathrm{~nm}$ & $719 \pm 132$ & $779 \pm 159$ & $703 \pm 153$ & $34 \pm 3$ \\
\hline CAPS - IONCs - $16 \mathrm{~nm}$ & $1073 \pm 175$ & $1092 \pm 201$ & $1072 \pm 193$ & $35 \pm 3$ \\
\hline CAPS - IONCs - $18 \mathrm{~nm}$ & $1396 \pm 260$ & $1356 \pm 244$ & $1232 \pm 208$ & $18 \pm 4$ \\
\hline WALLS - IONCs - $14 \mathrm{~nm}$ & $849 \pm 132$ & $934 \pm 202$ & $831 \pm 189$ & $22 \pm 2$ \\
\hline WALLS - IONCs - $16 \mathrm{~nm}$ & $1285 \pm 202$ & $1153 \pm 223$ & $1174 \pm 217$ & $38 \pm 3$ \\
\hline WALLS - IONCs - $18 \mathrm{~nm}$ & $706 \pm 148$ & $704 \pm 142$ & $665 \pm 125$ & $20 \pm 3$ \\
\hline
\end{tabular}

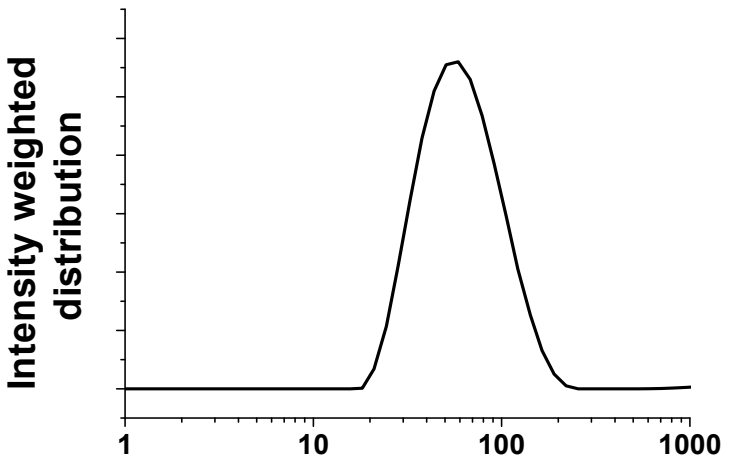

Hydrodynamic diameter [nm]

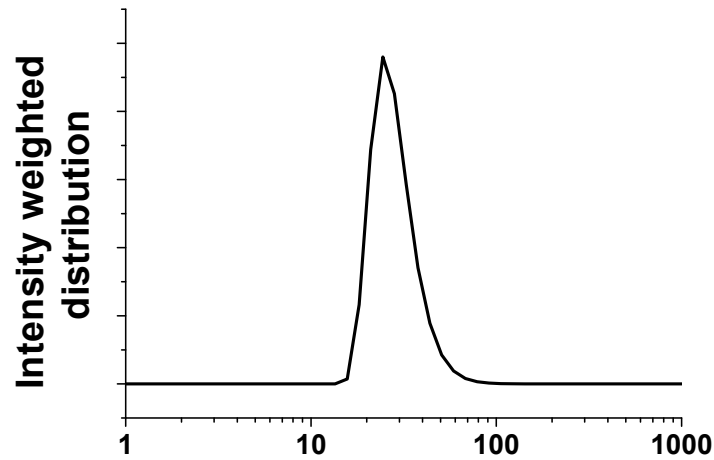

Hydrodynamic diameter [nm]

Figure S7: Intensity weighted distribution (left) and number weighted distribution (right) DLS traces of the 14 $n m$ IONCs. 


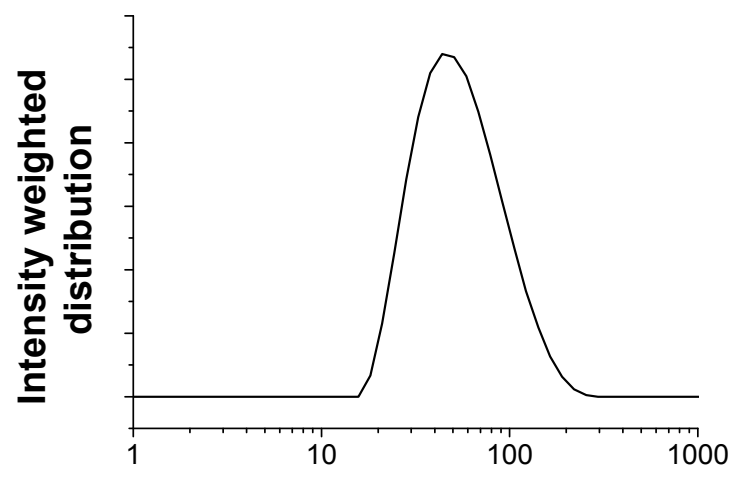

Hydrodynamic diameter [nm]

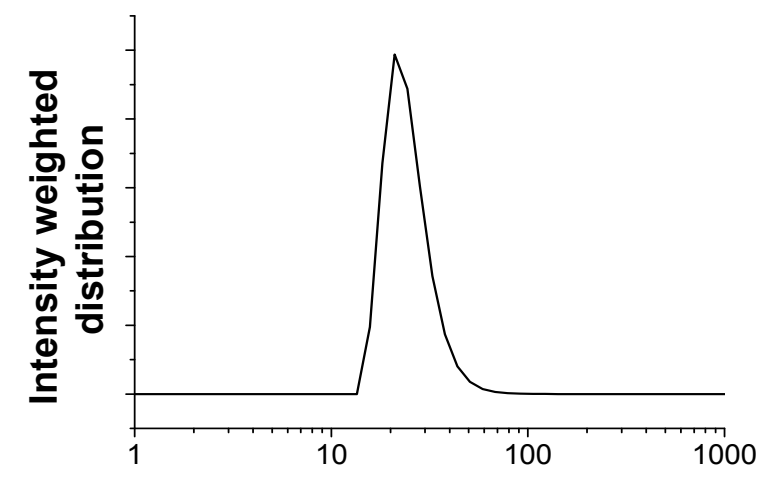

Hydrodynamic diameter [nm]

Figure S8: Intensity weighted distribution (left) and number weighted distribution (right) DLS traces of the 16 $n m$ IONCs.
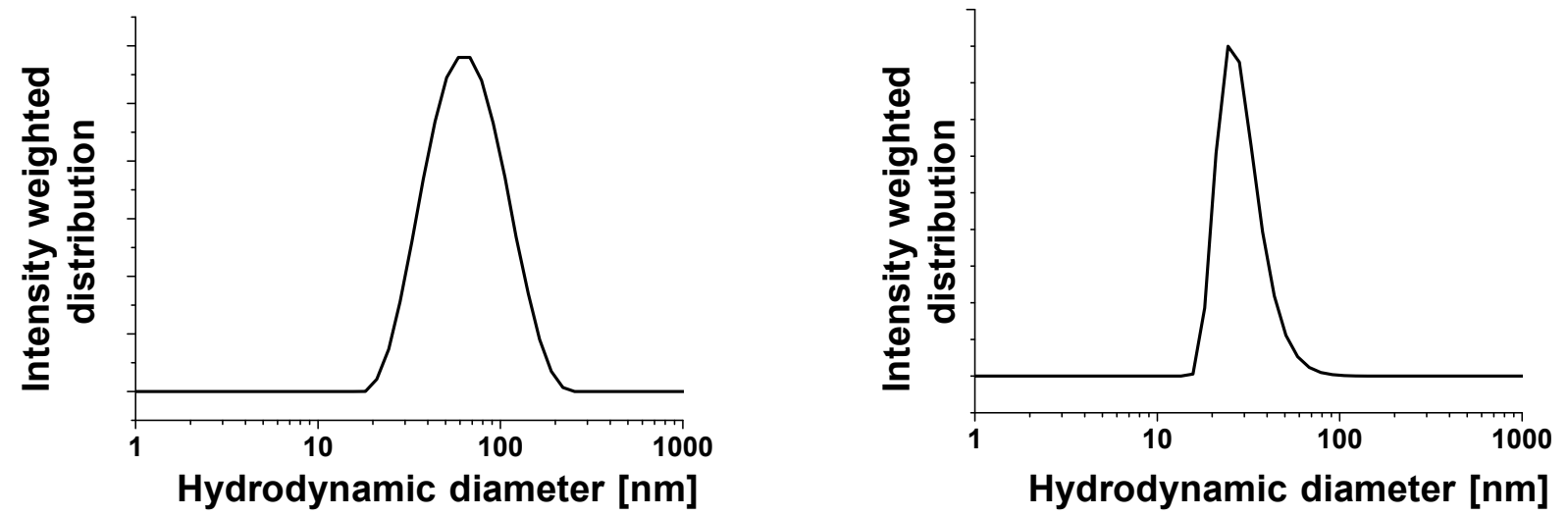

Figure S9: Intensity weighted distribution (left) and number weighted distribution (right) DLS traces of the 18 nm cubic IONCs. 

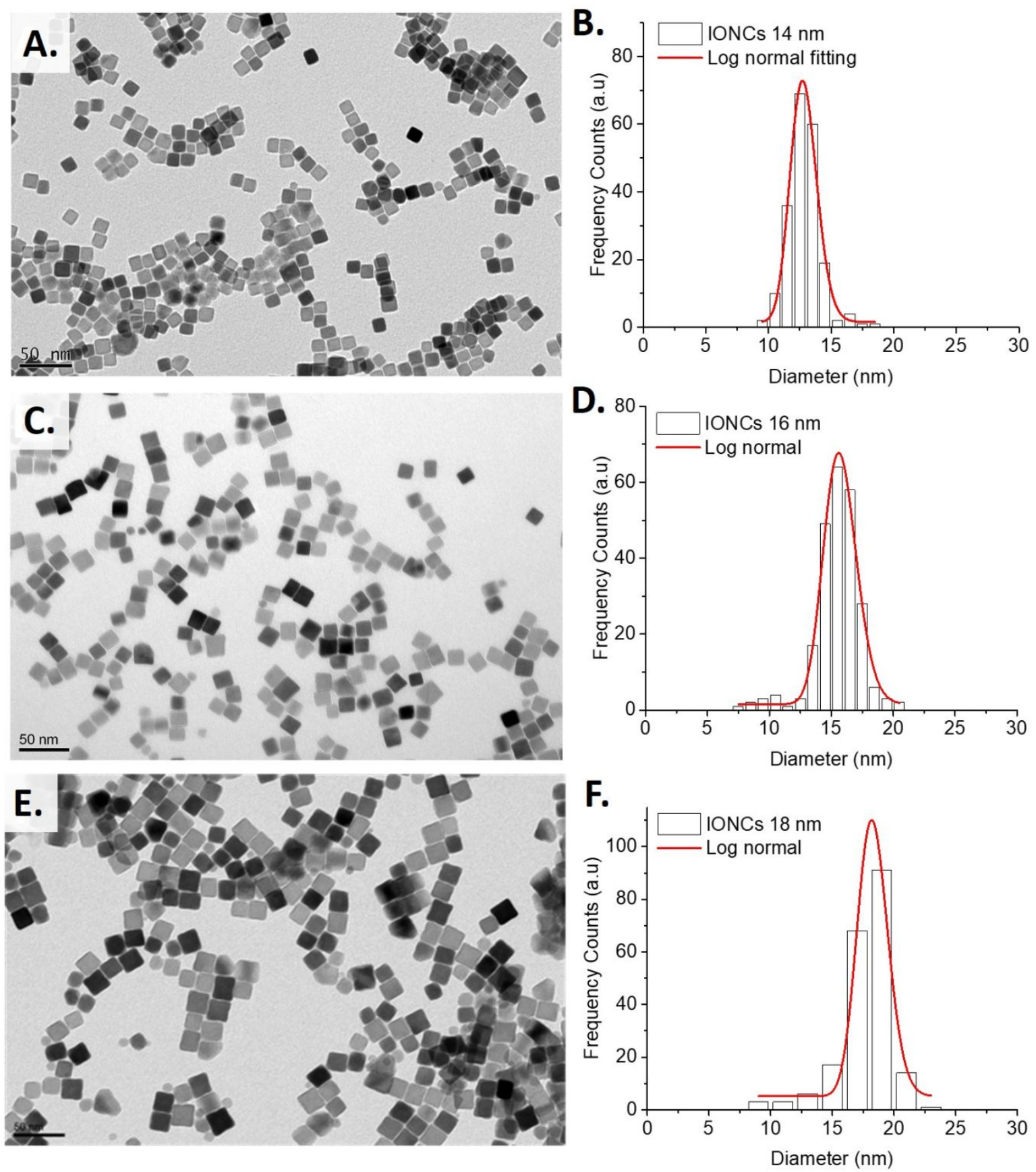

Figure S10: TEM images of the A. $14 \mathrm{~nm}, B .16 \mathrm{~nm}$, and C. $18 \mathrm{~nm}$ IONCs after water transfer. Size distribution of the samples of IONCS used to produce the capsules. The series of nanocubes have diameters of: D. $14 \pm$ $1 \mathrm{~nm}$ (standard deviation, $\sigma=0.10$ ), E. $16 \pm 2 \mathrm{~nm}$ (standard deviation, $\sigma=0.10$ ), and F. $18 \pm 2$ (standard deviation, $\sigma=0.10) \mathrm{nm}$. 
Table S2: Hydrodynamic diameters of PEG-coated $16 \mathrm{~nm}$ IONCS dispersed in different solvents.

\begin{tabular}{|c|c|}
\hline Solvent & $\begin{array}{c}\text { Hydrodynamic } \\
\text { diameter, [nm] }\end{array}$ \\
\hline water & $36 \pm 4$ \\
\hline $\mathrm{CaCl}_{2}(0.33 \mathrm{M})$ & $44 \pm 5$ \\
\hline $\mathrm{Na}_{2} \mathrm{CO}_{3}(0.33 \mathrm{M})$ & $377 \pm 18$ \\
\hline $\mathrm{EDTA}(0.2 \mathrm{M}, \mathrm{pH} 6)$ & $48 \pm 5$ \\
\hline cellular medium & $56 \pm 5$ \\
\hline
\end{tabular}



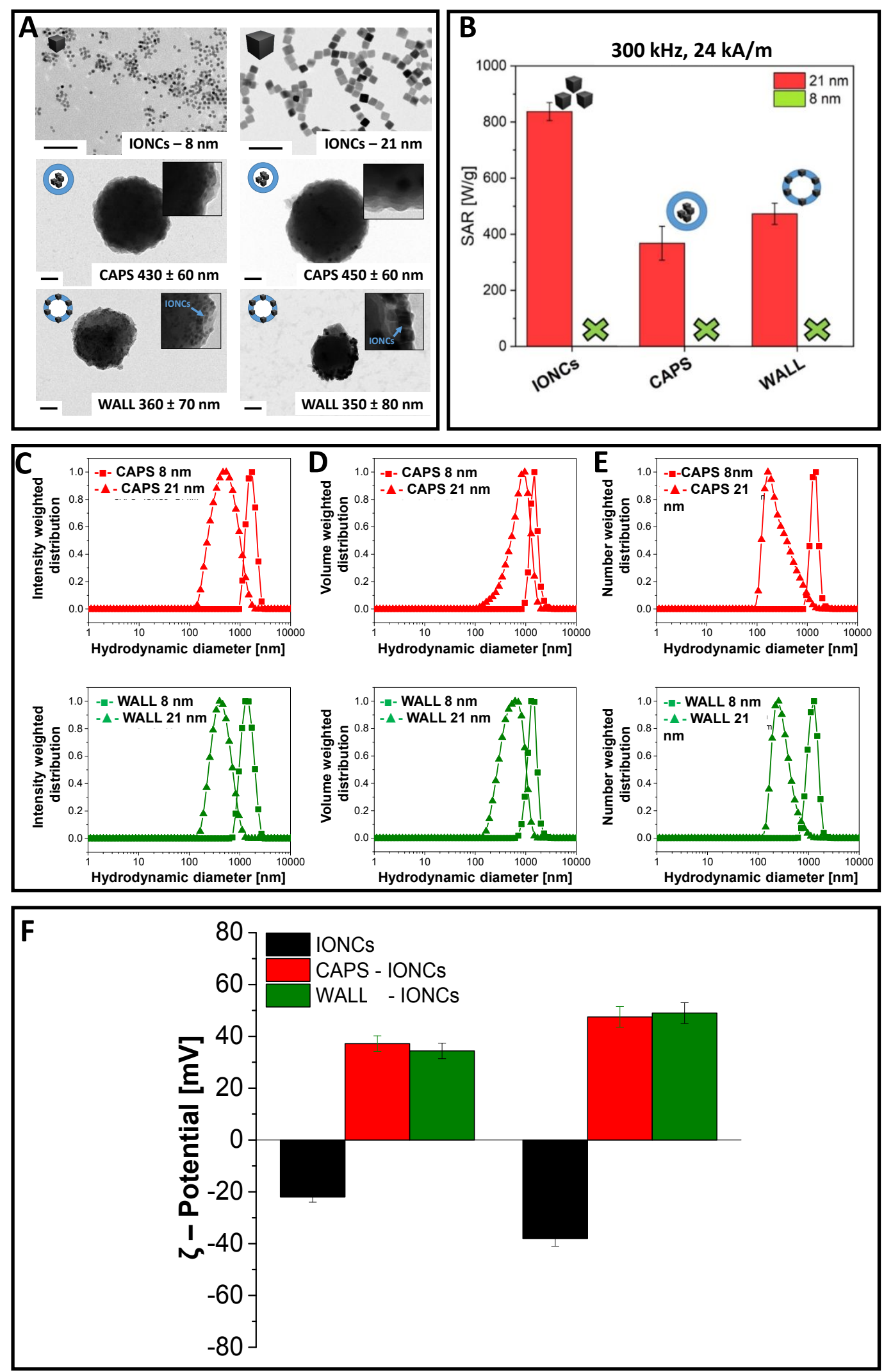

Figure S11: TEM (A), Specific absorption rate $(B)$, Hydrodynamic diameter $(C, D, E)$ and zeta potential $(F)$ characterization of CAPS and WALLS samples prepared with $8 \pm 1$ and $21 \pm 2 \mathrm{~nm}$ IONC samples. A) TEM images 
showing the IONCs. Inserts show the capsules' edges proving a higher density of IONCs in the edges of WALL samples compared to the CAPS samples. Scale bars for TEM images in A are $100 \mathrm{~nm}$. B) SAR values obtained by calorimetric measurements for free IONCS, CAPS and WALL dispersed in water at a Fe concentration of 1 $\mathrm{mg} / \mathrm{mL}$. The AMF conditions were set at $300 \mathrm{kHz}$ and $24 \mathrm{kA} / \mathrm{m}$. Under these measurements parameters, the $8 \mathrm{~nm}$ samples did not heat and no SAR values could be measured. This is due to their small size. (The green " $X$ " indicates the zero SAR values).
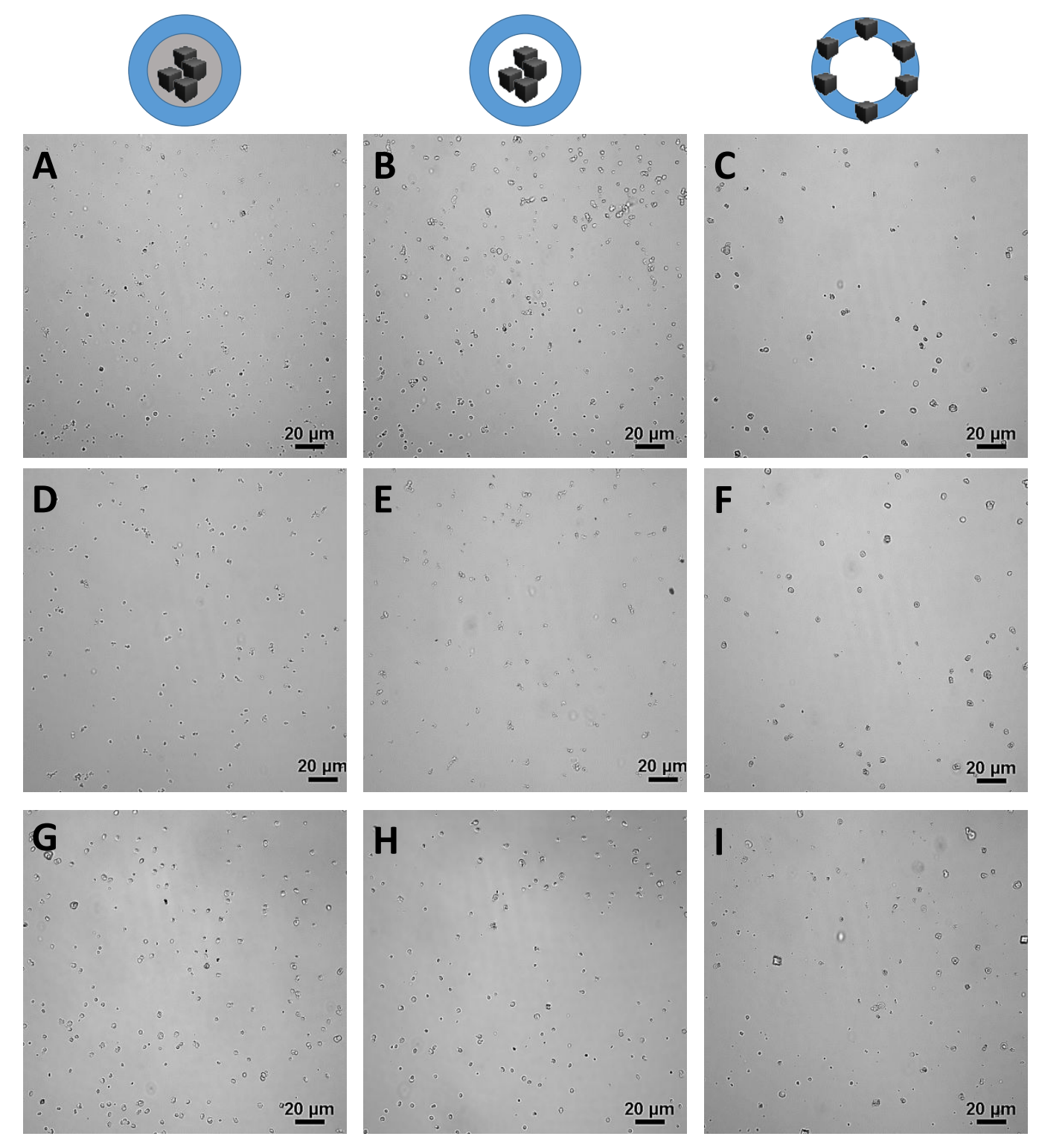

Figure S12: Representative bright field microscopy images of A. Cores with embedded $14 \mathrm{~nm}$ IONCS (CORES), B. Capsules with $14 \mathrm{~nm}$ IONCs in the cavity (CAPS), C. Capsules with $14 \mathrm{~nm}$ IONCs embedded in the wall (WALL), D. Cores with embedded $16 \mathrm{~nm}$ IONCs (CORES), E. Capsules with $16 \mathrm{~nm}$ IONCs in the cavity (CAPS), F. Capsules with $16 \mathrm{~nm}$ IONCs embedded in the wall (WALL), G. Cores with embedded $18 \mathrm{~nm}$ IONCS (CORES), H. Capsules with $18 \mathrm{~nm}$ IONCs in the cavity (CAPS), I. Capsules with $18 \mathrm{~nm}$ IONCs embedded in the wall (WALL). 

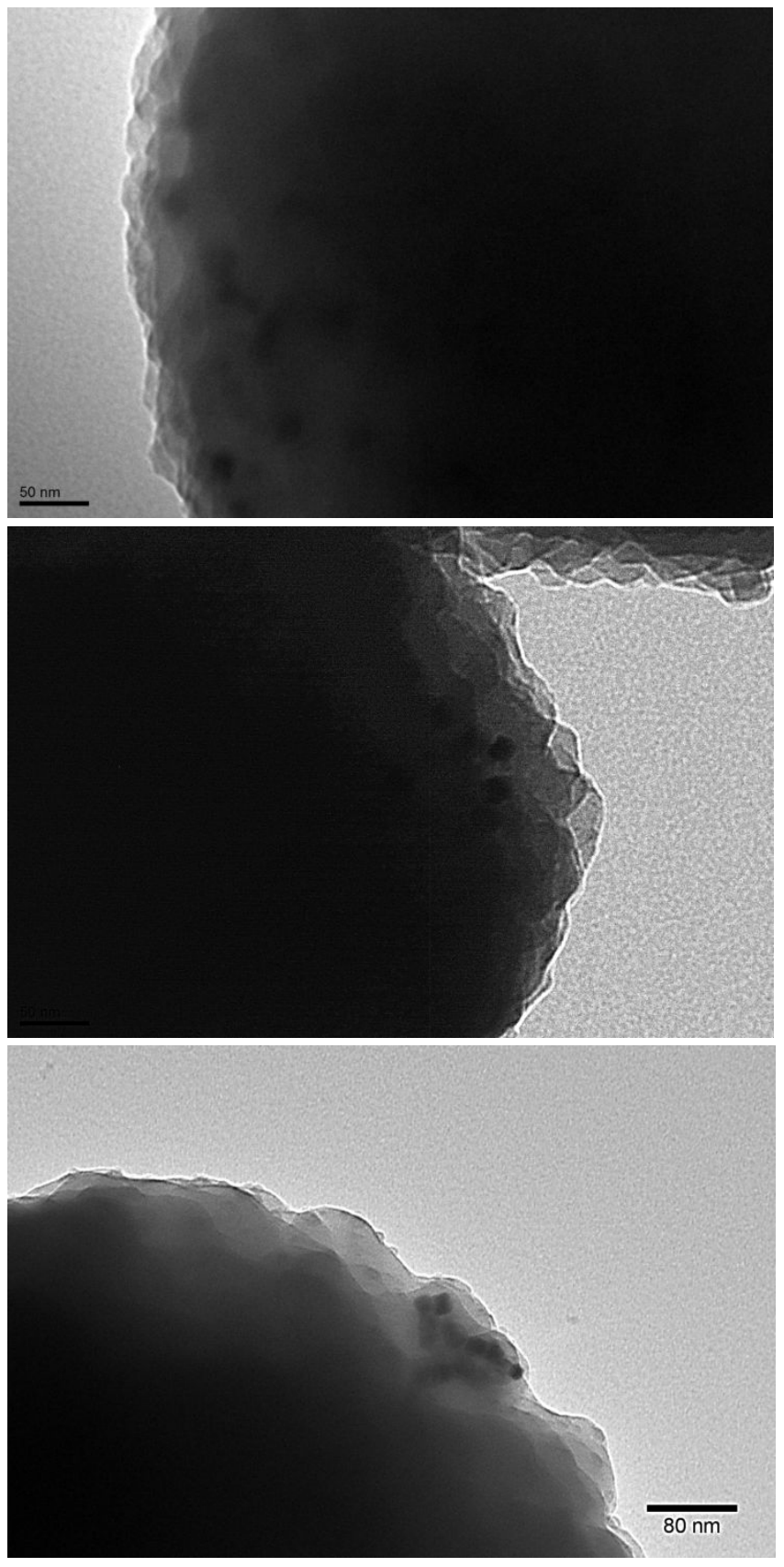

Figure S13: Representative TEM pictures of $\mathrm{CaCO}_{3}$ core particles in which $16 \mathrm{~nm}$ IONCs are encapsulated. 

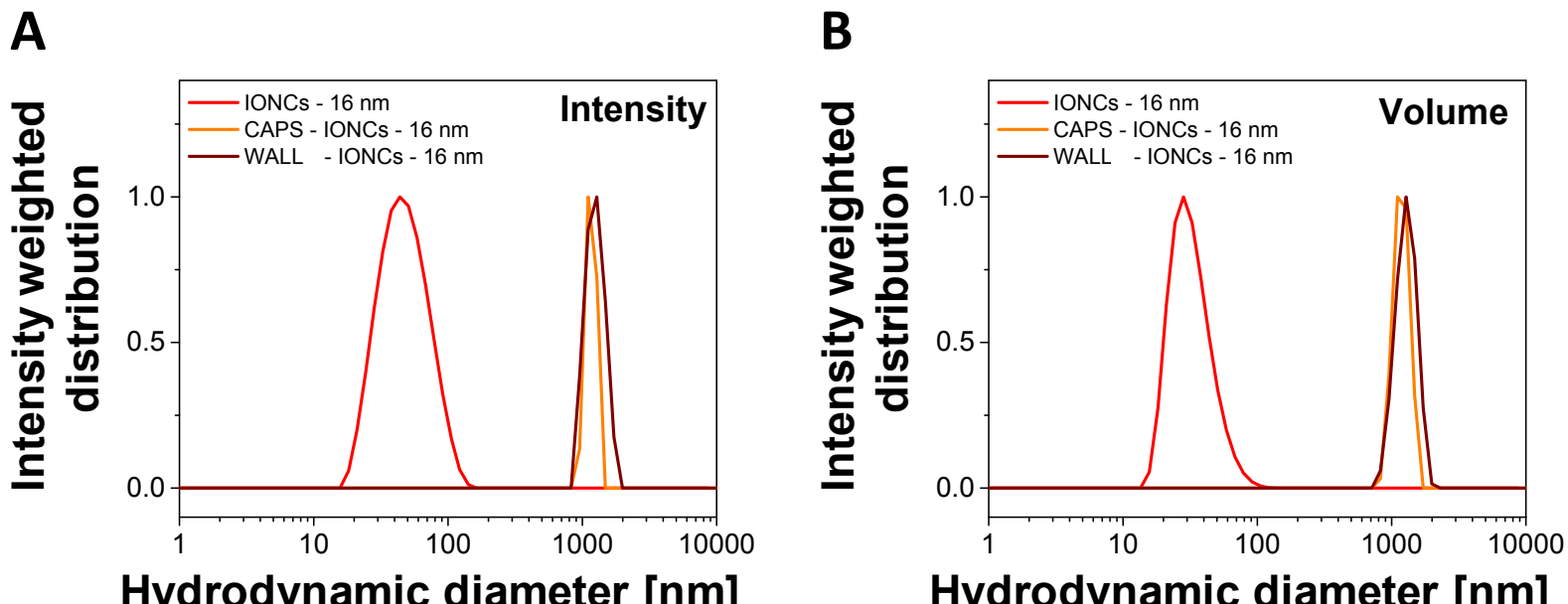

Hydrodynamic diameter [nm]

Hydrodynamic diameter [nm]

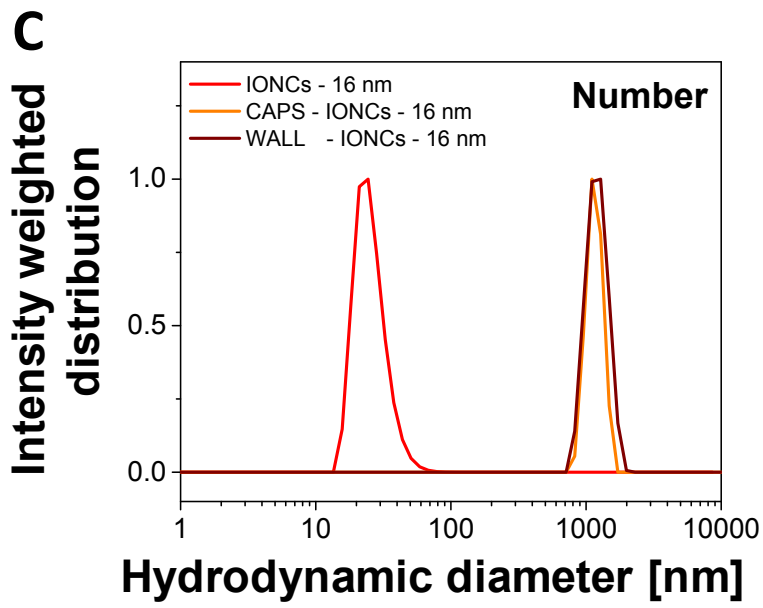

D

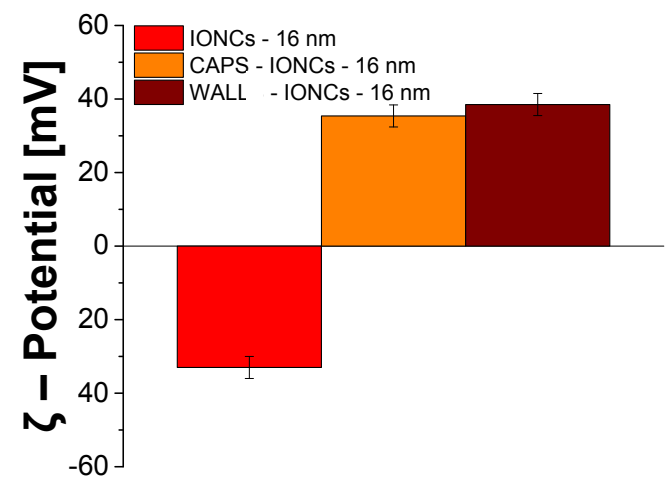

Figure S14: $(A-C)$ Hydrodynamic diameters in aqueous solutions measured by DLS for IONCs of $16 \pm 2 \mathrm{~nm}$ (red), and the corresponding CAPS (orange) and WALL (brown) samples as obtained when using the same IONCS sample. (A). CAPS and WALLS had very similar size as measured by TEM. The relative intensities of the hydrodynamic diameter have been normalized for an easy comparison of the samples. (D) Surface charge measured in term of $\zeta$-Potential by laser Doppler anenometry for the initial $16 \mathrm{~nm}$ IONCs (stabilized with nitrodopamine-carboxy-PEG), CAPS and WALLS. As expected, IONCs have a negatively charge because of the carboxylic acid terminated PEG ligands at the IONC surface, while CAPS and WALLS have a positive surface charge due to the outmost PAH polyelectrolyte layer that is positive. 


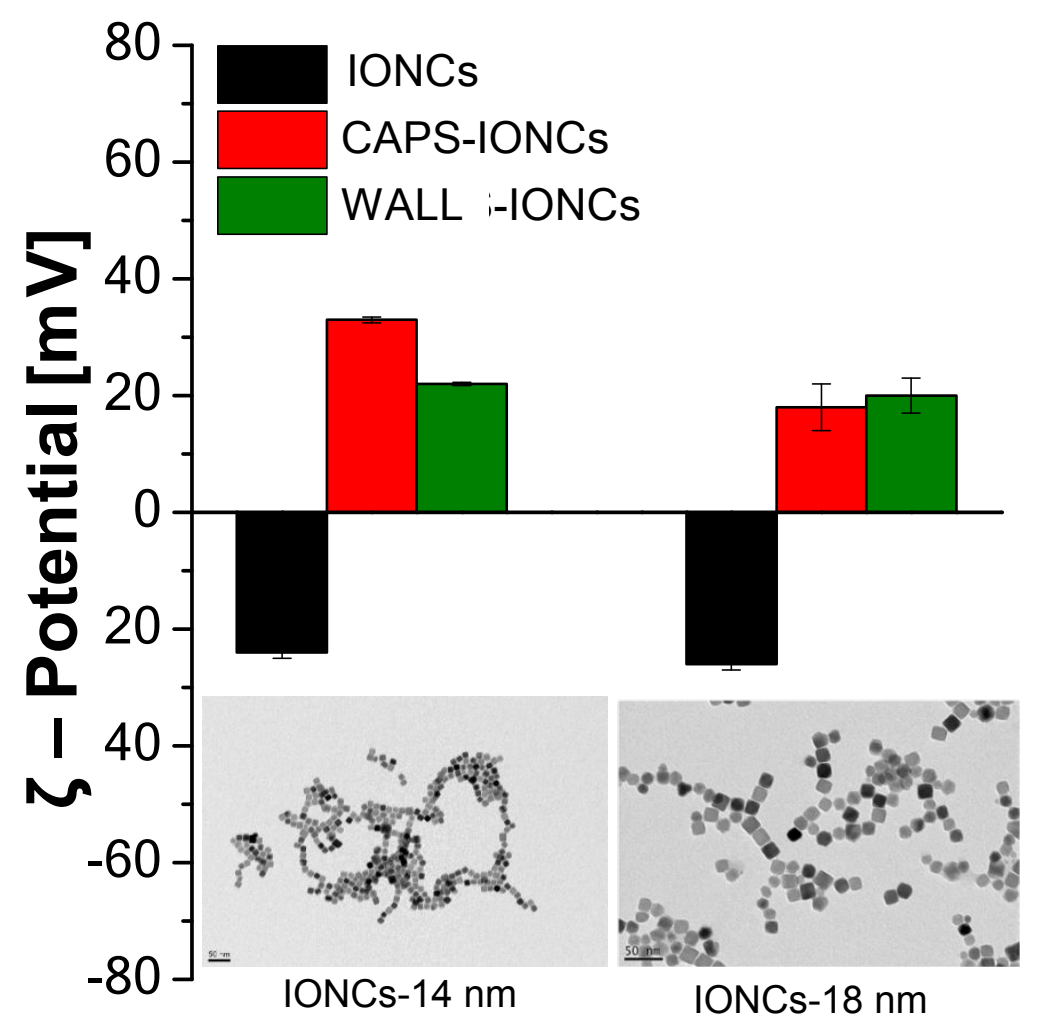

Figure S15: Zeta potential measurements of free IONCs, CAPS and WALL for 14 and $18 \mathrm{~nm}$ IONCs. TEM pictures of the free IONCs are shown. Scale bar correspond to $50 \mathrm{~nm}$.

Table S3: Specific heat capacity of used media. Values are given for $20^{\circ} \mathrm{C}$.

\begin{tabular}{|c|c|}
\hline Medium & Specific heat capacity $\left[\mathrm{J} /\left(\mathrm{cm}^{3} \cdot \mathrm{K}\right)\right]$ \\
\hline water & 4.185 \\
\hline glycerol $(36 \%)$ & 3.552 \\
\hline glycerol $(81 \%)$ & 2.659 \\
\hline SKOV-3 cells $\left(20 \cdot 10^{6}\right.$ in $\left.100 \mu \mathrm{L}\right)$ & 4.125 \\
\hline
\end{tabular}


Table S4: SAR values obtained by calorimetric measurements at different magnetic field conditions for magnetic nanomaterials synthesized with $16 \mathrm{~nm}$ IONCs.

\begin{tabular}{|c|c|c|}
\hline \multirow[t]{2}{*}{$d($ IONPs $)=16 \mathrm{~nm}$} & $\begin{array}{c}\text { SAR [W/g] } \\
302 \mathrm{kHz}, 24 \mathrm{kA} / \mathrm{m}\end{array}$ & $\begin{array}{c}\text { SAR [W/g] } \\
185 \mathrm{kHz}, 28 \mathrm{kA} / \mathrm{m}\end{array}$ \\
\hline & \multicolumn{2}{|c|}{ water } \\
\hline IONCS & $406 \pm 29$ & $285 \pm 45$ \\
\hline CORES & $196 \pm 10$ & $108 \pm 19$ \\
\hline CAPS & $234 \pm 46$ & $150 \pm 8$ \\
\hline WALL & $213 \pm 9$ & $135 \pm 18$ \\
\hline
\end{tabular}

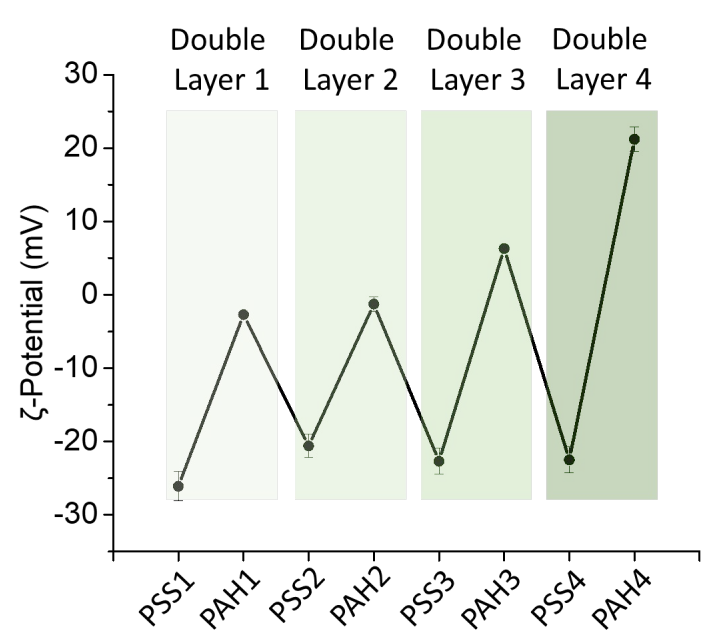

Figure S16: Monitoring of the $\zeta$-potential of the capsules during the LbL procedure. PAH is the positively charged polyelectrolyte layer: poly(allylaminehydrochloride); PSS is the negatively charged polyelectrolyte layer: poly(sodium 4-styrenesulfonate). 1, 2, 3, 4 refers to the numbers of the double layer deposited onto the capsules surface. One full double layer comprises one PAH layer on top of an PSS layer. 


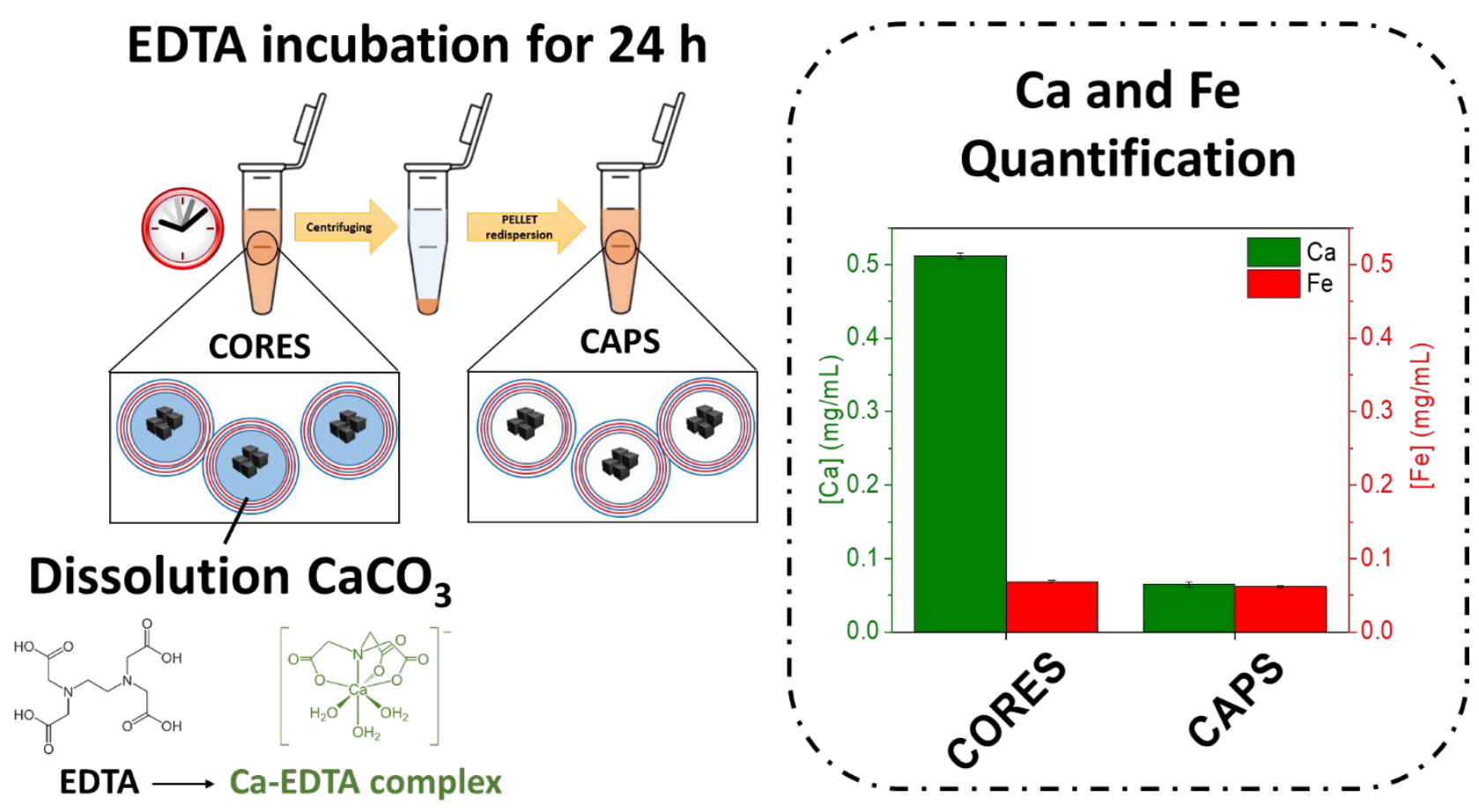

Figure S17: Calcium quantification before and after EDTA addition to the CORES sample to obtain the CAPS sample (when using $16 \mathrm{~nm}$ IONCS). After EDTA addition to CORES and an overnight incubation at room temperature, the sample was centrifuged and the Ca and Fe content was measured by Inductively Coupled Plasma - Atomic Emission Spectrometry (ICP-AES)on the pellet (containing the CAPS). The amount of Ca of the CAPS was reduced by $87 \%$ upon the incubation with EDTA with respect to the initial CORES sample. 
Table S5: SAR values obtained by calorimetric measurements at different magnetic field conditions for magnetic materials synthesized with $14 \mathrm{~nm}$ IONCs dispersed in different media.

\begin{tabular}{|c|c|c|c|c|c|c|c|c|c|}
\hline \multirow[t]{2}{*}{$d($ IONPs $)=14 \mathrm{~nm}$} & \multicolumn{3}{|c|}{$\begin{array}{c}\text { SAR [W/g] } \\
302 \mathrm{kHz}, 24 \mathrm{kA} / \mathrm{m}\end{array}$} & \multicolumn{3}{|c|}{$\begin{array}{c}\text { SAR [W/g] } \\
185 \mathrm{kHz}, 28 \mathrm{kA} / \mathrm{m}\end{array}$} & \multicolumn{3}{|c|}{$\begin{array}{c}\text { SAR [W/g] } \\
185 \mathrm{kHz}, 40 \mathrm{kA} / \mathrm{m}\end{array}$} \\
\hline & water & glycerol $36 \%$ & glycerol 81\% & water & glycerol $36 \%$ & glycerol $81 \%$ & water & glycerol $36 \%$ & glycerol $81 \%$ \\
\hline IONCS & $309 \pm 25$ & $299 \pm 2$ & $301 \pm 17$ & $190 \pm 17$ & $219 \pm 12$ & $191 \pm 20$ & $254 \pm 53$ & $260 \pm 12$ & $242 \pm 16$ \\
\hline CORES & $175 \pm 7$ & $178 \pm 2$ & $187 \pm 18$ & $114 \pm 7$ & $116 \pm 6$ & $116 \pm 16$ & $147 \pm 7$ & $139 \pm 3$ & $138 \pm 13$ \\
\hline CAPS & $193 \pm 15$ & $184 \pm 7$ & $188 \pm 4$ & $124 \pm 8$ & $116 \pm 9$ & $135 \pm 15$ & $161 \pm 17$ & $141 \pm 4$ & $165 \pm 12$ \\
\hline WALL & $158 \pm 20$ & $175 \pm 14$ & $157 \pm 10$ & $112 \pm 21$ & $99 \pm 1$ & $114 \pm 18$ & $153 \pm 6$ & $139 \pm 20$ & $142 \pm 27$ \\
\hline
\end{tabular}

Table S6: SAR values obtained by calorimetric measurements at different magnetic field conditions for magnetic materials synthesized with $18 \mathrm{~nm}$ IONCs dispersed in different media.

\begin{tabular}{|c|c|c|c|c|c|c|c|c|c|}
\hline \multirow[t]{2}{*}{$d($ IONPs $)=18 \mathrm{~nm}$} & \multicolumn{3}{|c|}{$\begin{array}{c}\text { SAR [W/g] } \\
302 \mathrm{kHz}, 24 \mathrm{kA} / \mathrm{m}\end{array}$} & \multicolumn{3}{|c|}{$\begin{array}{c}\text { SAR [W/g] } \\
185 \mathrm{kHz}, 28 \mathrm{kA} / \mathrm{m}\end{array}$} & \multicolumn{3}{|c|}{$\begin{array}{c}\text { SAR [W/g] } \\
185 \mathrm{kHz}, 40 \mathrm{kA} / \mathrm{m}\end{array}$} \\
\hline & water & glycerol 36\% & glycerol $81 \%$ & water & glycerol $36 \%$ & glycerol $81 \%$ & water & glycerol $36 \%$ & glycerol 81\% \\
\hline IONCS & $503 \pm 58$ & $493 \pm 37$ & $288 \pm 29$ & $297 \pm 16$ & $342 \pm 24$ & $206 \pm 29$ & $454 \pm 5$ & $415 \pm 27$ & $271 \pm 5$ \\
\hline CORES & $165 \pm 36$ & $160 \pm 8$ & $185 \pm 39$ & $100 \pm 35$ & $113 \pm 1$ & $119 \pm 15$ & $161 \pm 3$ & $147 \pm 27$ & $168 \pm 15$ \\
\hline CAPS & $246 \pm 23$ & $235 \pm 13$ & $256 \pm 20$ & $160 \pm 12$ & $154 \pm 11$ & $176 \pm 11$ & $233 \pm 22$ & $209 \pm 3$ & $232 \pm 16$ \\
\hline WALL & $197 \pm 16$ & $160 \pm 3$ & $174 \pm 12$ & $135 \pm 19$ & $85 \pm 10$ & $121 \pm 12$ & $172 \pm 9$ & $114 \pm 10$ & $135 \pm 16$ \\
\hline
\end{tabular}




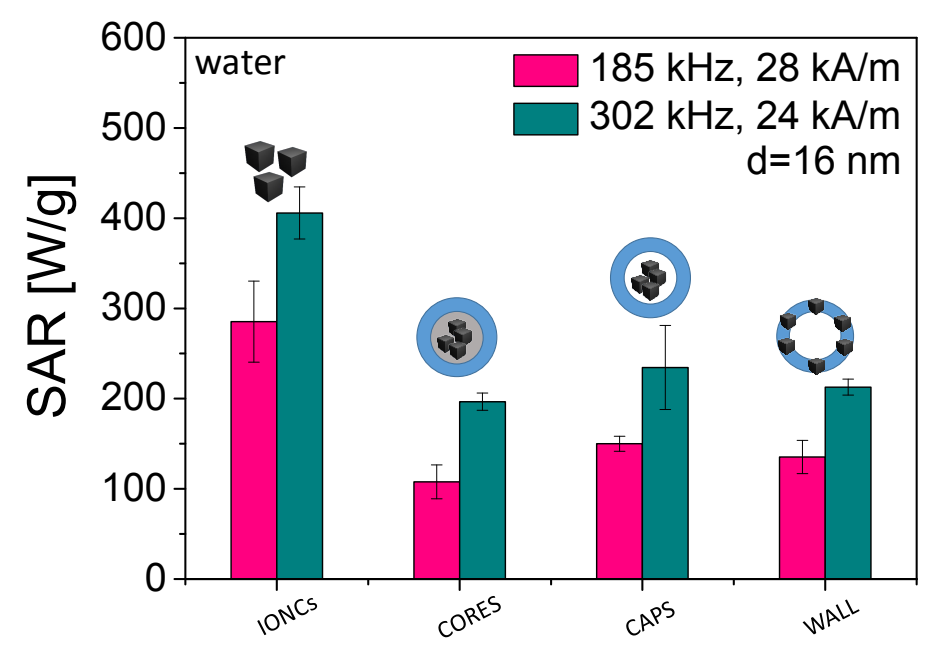

Figure S18: SAR values obtained by calorimetric measurements for free IONCS $(d=16 \mathrm{~nm})$, calcium carbonate cores with immobilized IONCS coated with polyelectrolytes (CORES), polyelectrolyte capsules loaded with IONCs into the cavity (CAPS), and polyelectrolyte capsules with embedded IONCs in the capsules' walls (WALL) dispersed in water at different field conditions (185 kHz and $28 \mathrm{kA} / \mathrm{m}$ and $302 \mathrm{kHz}$ and $24 \mathrm{kA} / \mathrm{m}$ ).

A

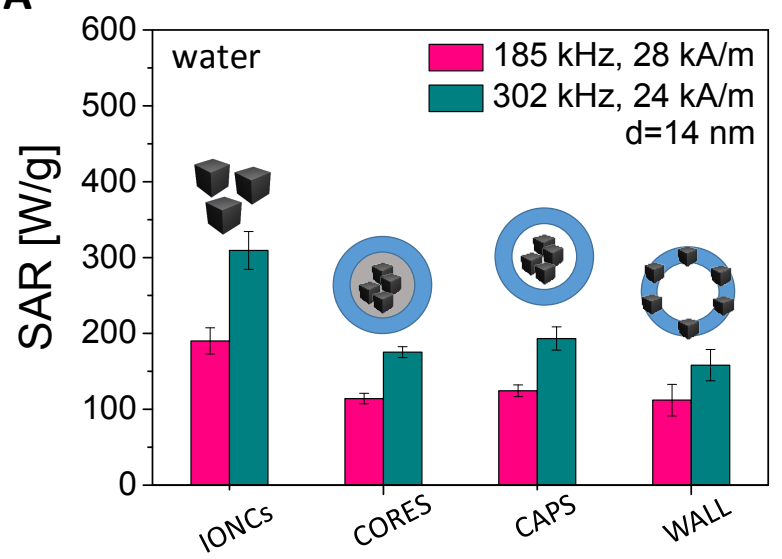

B

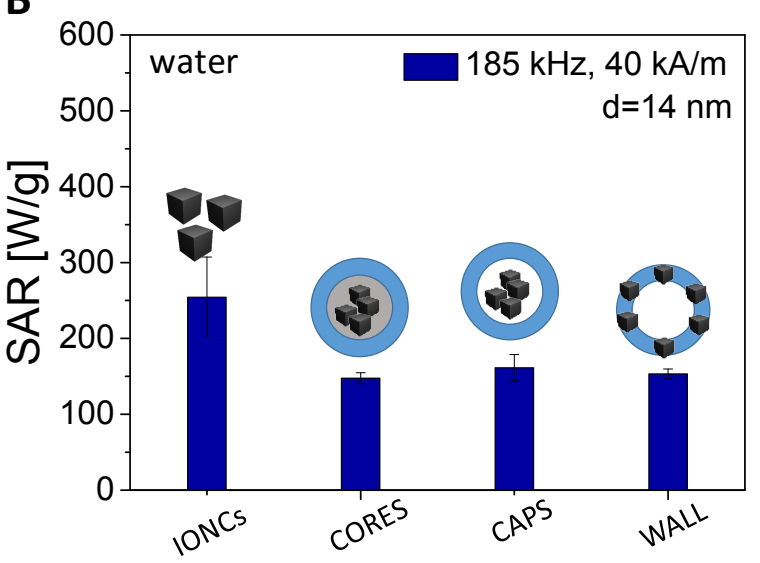

Figure S19: SAR values obtained by calorimetric measurements for free IONCs ( $d=14 \mathrm{~nm})$, calcium carbonate cores with immobilized IONCs coated with polyelectrolytes (CORES), polyelectrolyte capsules loaded with IONCs into the cavity (CAPS), and polyelectrolyte capsules with embedded IONCs in the capsules' walls (WALL) at $A .185 \mathrm{kHz}$ and $28 \mathrm{kA} / \mathrm{m}, 302 \mathrm{kHz}$ and $28 \mathrm{kA} / \mathrm{m}, \mathrm{B} .185 \mathrm{kHz}$ and $40 \mathrm{kA} / \mathrm{m}$ dispersed in water. 
A

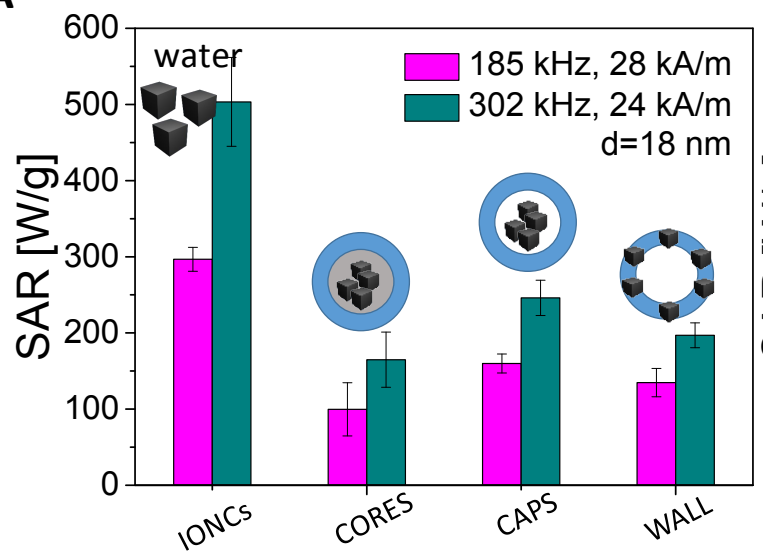

B

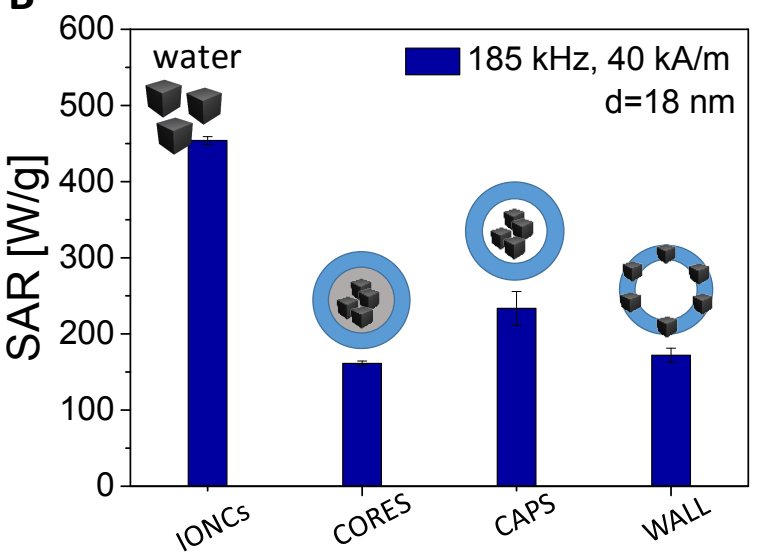

Figure S20: SAR values obtained by calorimetric measurements for free IONCS $(d=18 \mathrm{~nm})$, calcium carbonate cores with immobilized IONCs coated with polyelectrolytes (CORES), polyelectrolyte capsules loaded with IONCs into the cavity (CAPS), and polyelectrolyte capsules with embedded IONCs in the capsules' walls (WALL) at A. $185 \mathrm{kHz}$ and $28 \mathrm{kA} / \mathrm{m}, 302 \mathrm{kHz}$ and $28 \mathrm{kA} / \mathrm{m}, \mathrm{B} .185 \mathrm{kHz}$ and $40 \mathrm{kA} / \mathrm{m}$ dispersed in water.

A

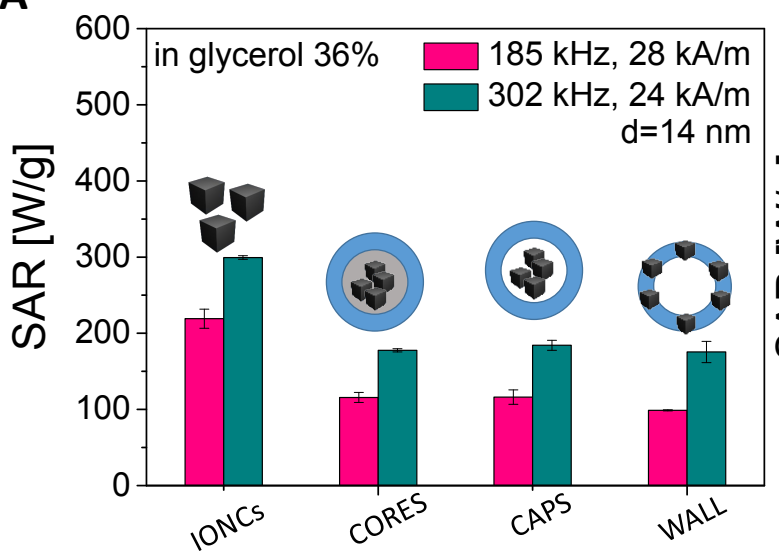

B

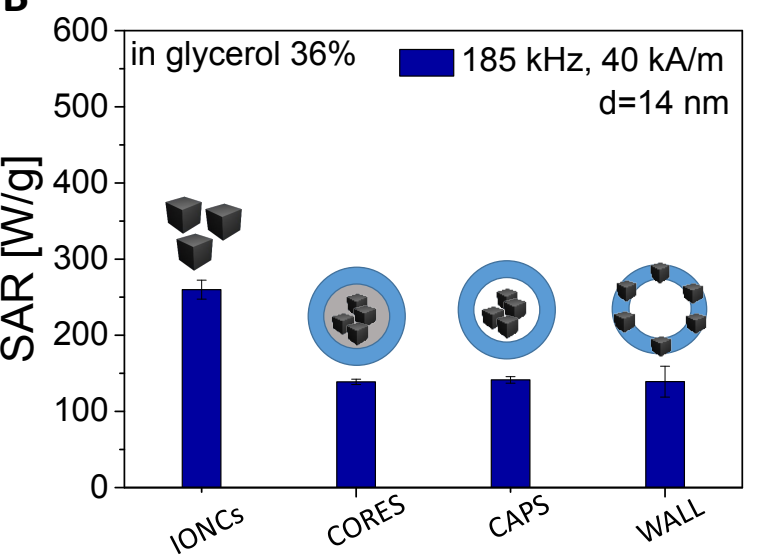

Figure S21: SAR values obtained by calorimetric measurements for free IONCS $(d=14 \mathrm{~nm})$, calcium carbonate cores with immobilized IONCs coated with polyelectrolytes (CORES), polyelectrolyte capsules loaded with IONCs into the cavity (CAPS), and polyelectrolyte capsules with embedded IONCs in the capsules' walls (WALL) at $A .185 \mathrm{kHz}$ and $28 \mathrm{kA} / \mathrm{m}, 302 \mathrm{kHz}$ and $28 \mathrm{kA} / \mathrm{m}, \mathrm{B} .185 \mathrm{kHz}$ and $40 \mathrm{kA} / \mathrm{m}$ dispersed in glycerol $36 \%$. 
A

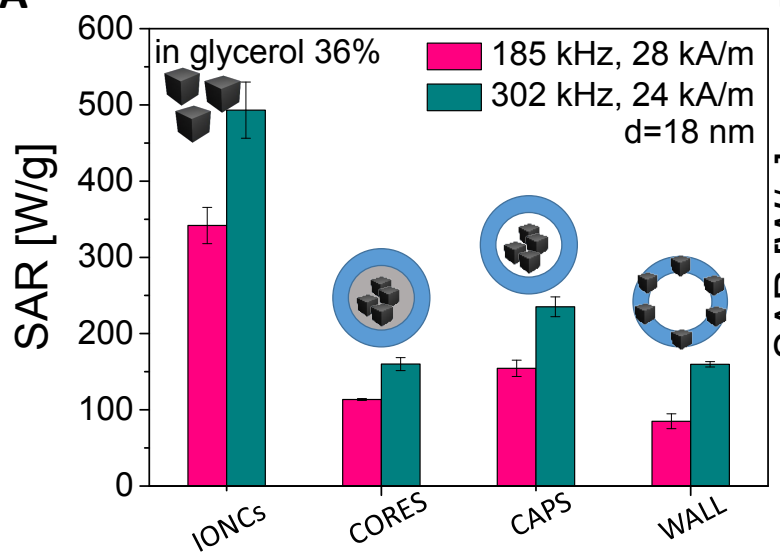

B

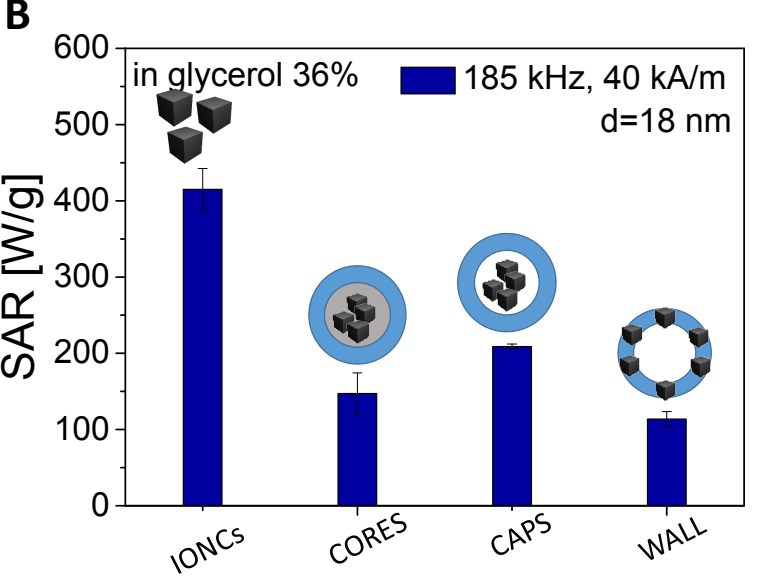

Figure S22: SAR values obtained by calorimetric measurements for free IONCS $(d=18 \mathrm{~nm})$, calcium carbonate cores with immobilized IONCs coated with polyelectrolytes (CORES), polyelectrolyte capsules loaded with IONCs into the cavity (CAPS), and polyelectrolyte capsules with embedded IONCs in the capsules' walls (WALL) at A. $185 \mathrm{kHz}$ and $28 \mathrm{kA} / \mathrm{m}, 302 \mathrm{kHz}$ and $28 \mathrm{kA} / \mathrm{m}, \mathrm{B} .185 \mathrm{kHz}$ and $40 \mathrm{kA} / \mathrm{m}$ dispersed in glycerol 36\%.

A

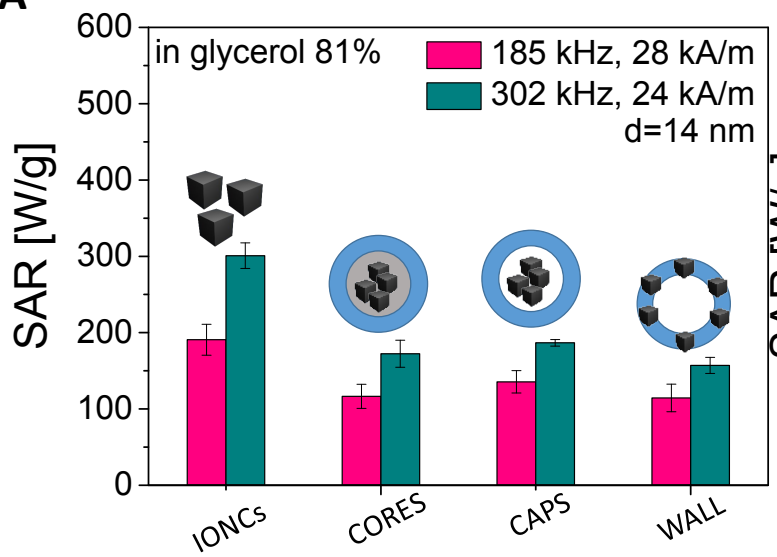

B

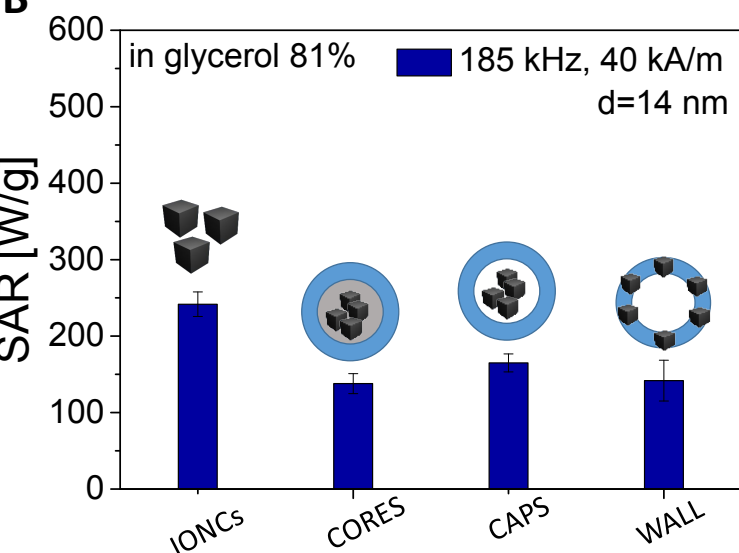

Figure S23: SAR values obtained by calorimetric measurements for free IONCs $(d=14 \mathrm{~nm})$, calcium carbonate cores with immobilized IONCs coated with polyelectrolytes (CORES), polyelectrolyte capsules loaded with IONCs into the cavity (CAPS), and polyelectrolyte capsules with embedded IONCs in the capsules' walls (WALL) at A. $185 \mathrm{kHz}$ and $28 \mathrm{kA} / \mathrm{m}, 302 \mathrm{kHz}$ and $28 \mathrm{kA} / \mathrm{m}, \mathrm{B} .185 \mathrm{kHz}$ and $40 \mathrm{kA} / \mathrm{m}$ dispersed in glycerol $81 \%$. 
A

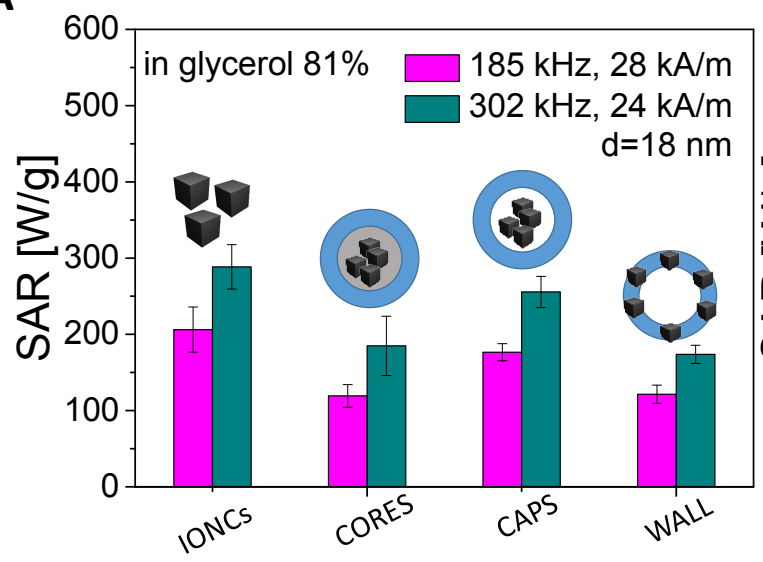

B

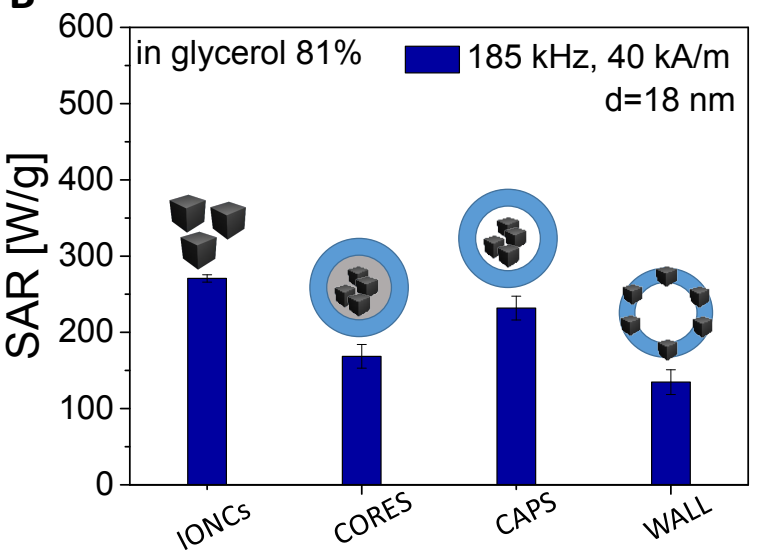

Figure S24: SAR values obtained by calorimetric measurements for free IONCS $(d=18 \mathrm{~nm})$, calcium carbonate cores with immobilized IONCs coated with polyelectrolytes (CORES), polyelectrolyte capsules loaded with IONCS into the cavity (CAPS), and polyelectrolyte capsules with embedded IONCs in the capsules' walls (WALL) at $A .185 \mathrm{kHz}$ and $28 \mathrm{kA} / \mathrm{m}, 302 \mathrm{kHz}$ and $28 \mathrm{kA} / \mathrm{m}, \mathrm{B} .185 \mathrm{kHz}$ and $40 \mathrm{kA} / \mathrm{m}$ dispersed in glycerol $81 \%$.

Magnetic properties

A

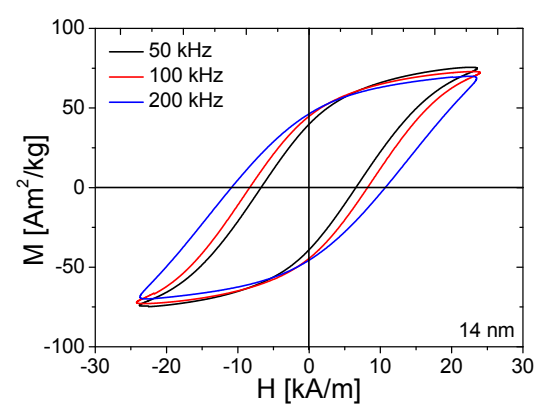

B

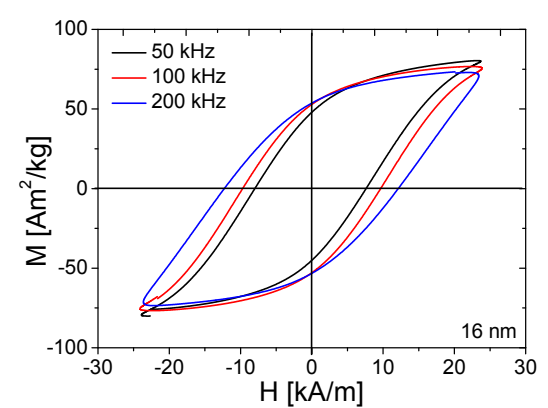

C

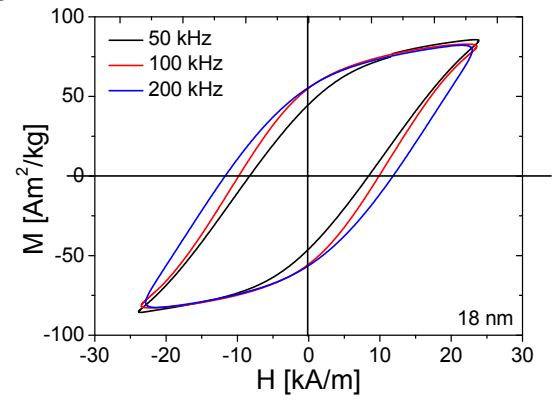

Figure S25: Frequency dependence of AC hysteresis loops of different magnetic nanomaterials dispersed in water A. $14 \mathrm{~nm}$ IONCS, B. $16 \mathrm{~nm}$ IONCs, C. $18 \mathrm{~nm}$ IONCs. Measurements were performed at $24 \mathrm{kA} / \mathrm{m}$ and at $1.5 \mathrm{~g}(\mathrm{Fe}) / \mathrm{L}$. 
A

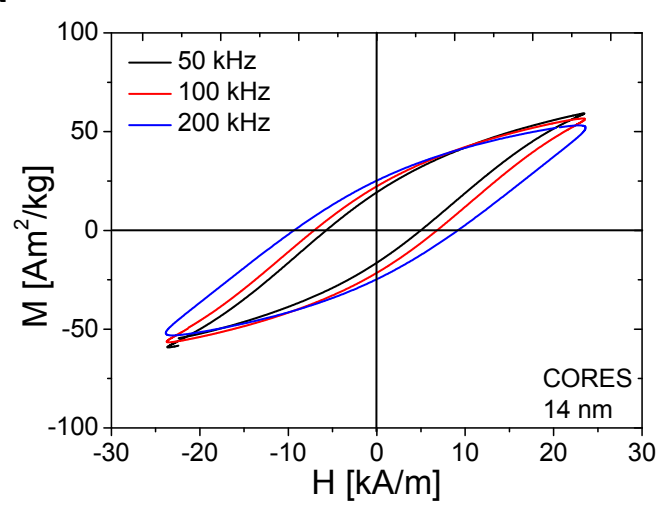

B

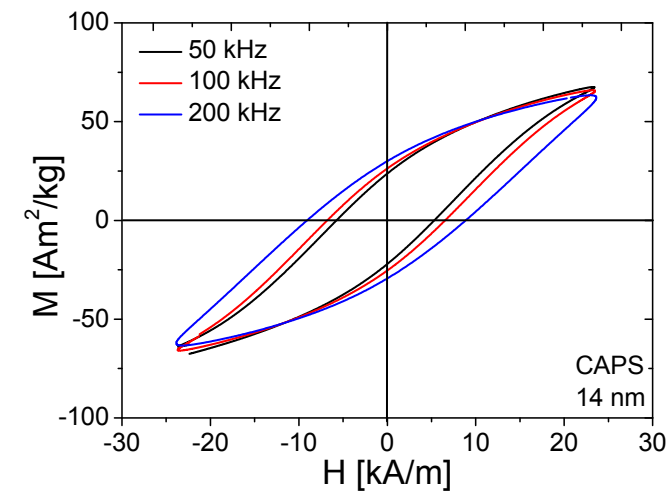

C

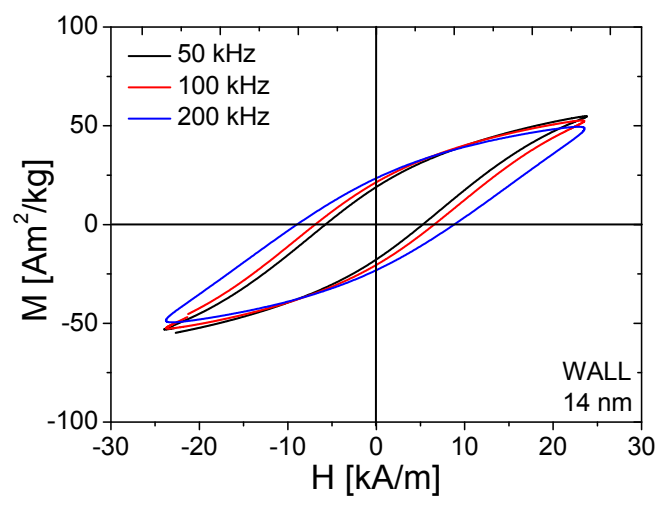

Figure S26: Frequency dependence of AC hysteresis loops of different magnetic nanomaterials dispersed in water $\mathrm{A} . \mathrm{CaCO}_{3}$ cores with embedded $14 \mathrm{~nm}$ IONCs in the cavity (CORES), B. capsules with $14 \mathrm{~nm}$ IONCs in the cavity (CAPS), C. capsules with $14 \mathrm{~nm}$ IONCs in the wall (WALL). Measurements were performed at $24 \mathrm{kA} / \mathrm{m}$ and at $1.5 \mathrm{~g}(\mathrm{Fe}) / \mathrm{L}$. 
A

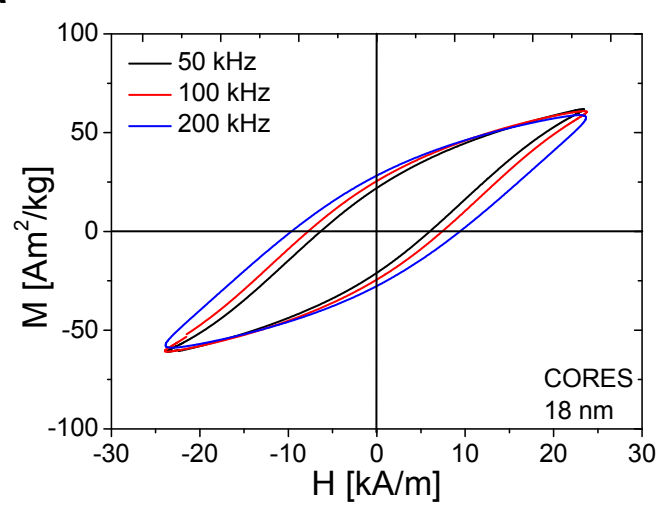

B

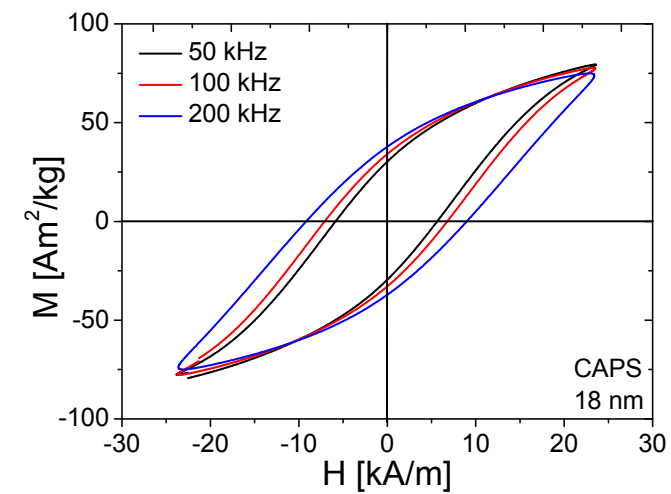

C

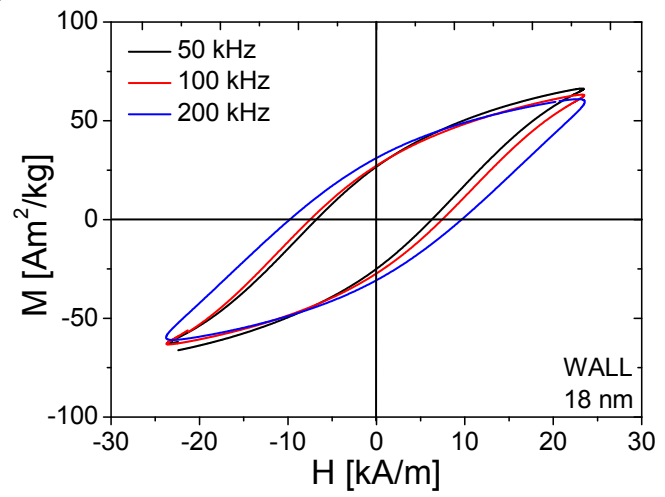

Figure S27: Frequency dependence of AC hysteresis loops of different magnetic nanomaterials dispersed in water: $\mathrm{A} . \mathrm{CaCO}_{3}$ cores with embedded $18 \mathrm{~nm}$ IONCs in the cavity (CORES), B. capsules with $18 \mathrm{~nm}$ IONCs in the cavity (CAPS), C. capsules with $18 \mathrm{~nm}$ IONCs in the wall (WALL). Measurements were performed at 24 $k A / m$ and at $1.5 \mathrm{~g}(\mathrm{Fe}) / \mathrm{L} r$. 
Table S7: Areas and SAR values obtained by AC magnetometry ${ }^{3}$ from the distinct magnetic nanomaterials at different magnetic field conditions.

\begin{tabular}{|c|c|c|}
\hline & $\begin{array}{c}A(\mathrm{~mJ} / \mathrm{kg}) / \mathrm{SAR}(\mathrm{W} / \mathrm{g}) \text { at } \\
50 \mathrm{kHz} \text { and } 24 \mathrm{kA} / \mathrm{m}\end{array}$ & $\begin{array}{c}A(\mathrm{~mJ} / \mathrm{kg}) / \mathrm{SAR}(\mathrm{W} / \mathrm{g}) \text { at } \\
200 \mathrm{kHz} \text { and } 24 \mathrm{kA} / \mathrm{m}\end{array}$ \\
\hline IONCs, 14 nm & $2251 / 112$ & $2664 / 532$ \\
\hline CORES, 14 nm & $1027 / 51$ & $1480 / 296$ \\
\hline CAPS, 14 nm & $1249 / 62$ & $1702 / 340$ \\
\hline WALL, 14 nm & $727 / 36$ & $1345 / 270$ \\
\hline IONCs, 18 nm & $2881 / 144$ & $3453 / 690$ \\
\hline CORES, 18 nm & $1166 / 58$ & $1686 / 338$ \\
\hline CAPS, 18 nm & $1608 / 80$ & $2104 / 420$ \\
\hline WALL, 18 nm & $1431 / 71$ & $1942 / 388$ \\
\hline
\end{tabular}


Magnetic attraction after cellular internalization.

A

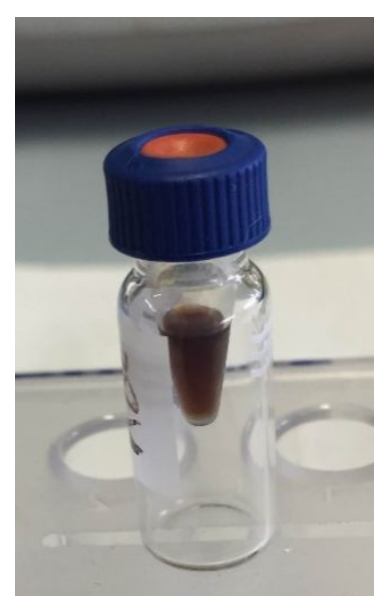

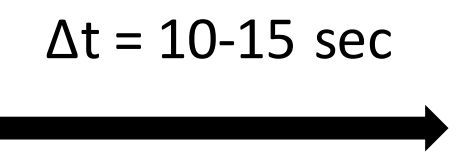

$18 \mathrm{~nm}$ IONCs

B

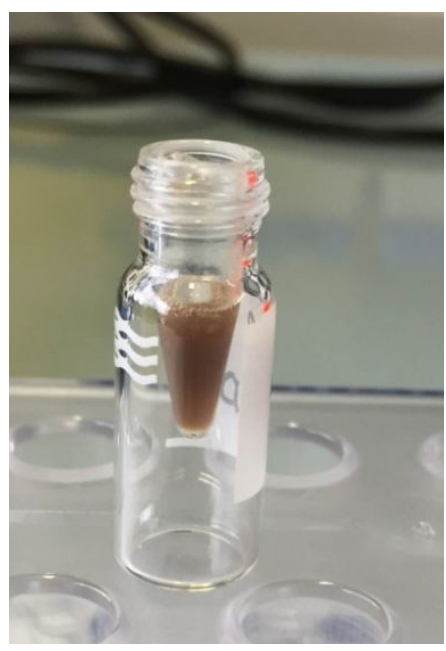

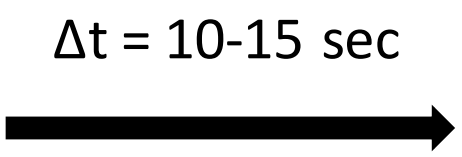

Cells with $18 \mathrm{~nm}$ IONCs
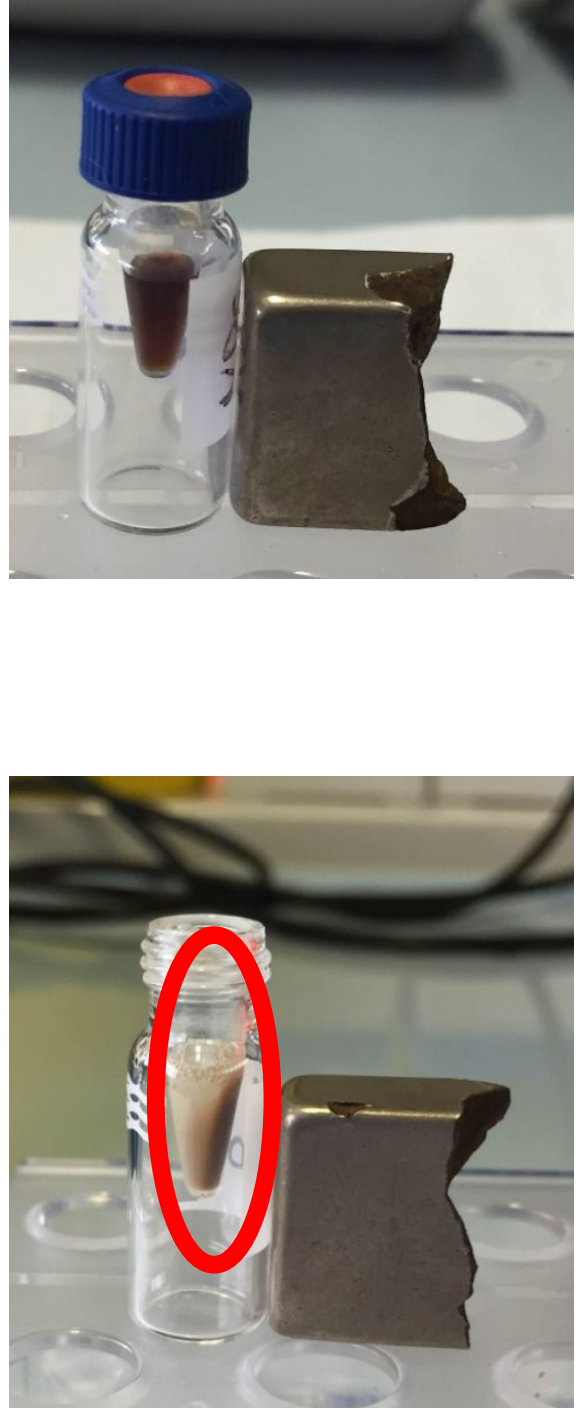

Figure S28: Attraction of free IONCs $(18 \mathrm{~nm})$ to the magnet $A$. without cells, $B$. with cells. 
Table S8: SAR values obtained by calorimetric measurements for magnetic materials synthesized IONCS interacting with SKOV-3 cells at different time periods.

\begin{tabular}{|c|c|c|c|c|c|}
\hline \multirow[t]{2}{*}{$d($ IONPs $)=14 \mathrm{~nm}$} & \multicolumn{5}{|c|}{$\begin{array}{c}\text { SAR [W/g] } \\
302 \mathrm{kHz}, 24 \mathrm{kA} / \mathrm{m}\end{array}$} \\
\hline & \multicolumn{2}{|c|}{$15 \mathrm{~min}$} & $45 \mathrm{~min}$ & $90 \mathrm{~min}$ & $180 \mathrm{~min}$ \\
\hline IONCS & $243 \pm 30$ & $217 \pm 54$ & $152 \pm 26$ & $139 \pm 23$ & $111 \pm 23$ \\
\hline CAPS & $132 \pm 16$ & $140 \pm 14$ & $145 \pm 16$ & $140 \pm 23$ & $147 \pm 15$ \\
\hline WALL & $115 \pm 8$ & $125 \pm 7$ & $91 \pm 17$ & $100 \pm 20$ & $92 \pm 7$ \\
\hline \multirow[t]{2}{*}{$d($ IONPs $)=18 \mathrm{~nm}$} & \multicolumn{5}{|c|}{$\begin{array}{c}\text { SAR [W/g] } \\
302 \mathrm{kHz}, 24 \mathrm{kA} / \mathrm{m}\end{array}$} \\
\hline & $0 \mathrm{~min}$ & $15 \mathrm{~min}$ & $45 \mathrm{~min}$ & $90 \mathrm{~min}$ & $180 \mathrm{~min}$ \\
\hline IONCs & $353 \pm 19$ & $231 \pm 26$ & $201 \pm 18$ & $159 \pm 40$ & $145 \pm 30$ \\
\hline CAPS & $182 \pm 27$ & $153 \pm 12$ & $145 \pm 30$ & $137 \pm 24$ & $140 \pm 12$ \\
\hline WALL & $151 \pm 8$ & $119 \pm 13$ & $117 \pm 5$ & $123 \pm 4$ & $122 \pm 2$ \\
\hline \multicolumn{6}{|c|}{$\begin{array}{c}\text { SAR [W/g] } \\
302 \mathrm{kHz}, 24 \mathrm{kA} / \mathrm{m}\end{array}$} \\
\hline & \multicolumn{3}{|c|}{$24 \mathrm{~h}$} & \multicolumn{2}{|c|}{$48 \mathrm{~h}$} \\
\hline & $\mathrm{d}($ IONCs $)=14 \mathrm{~nm}$ & \multicolumn{2}{|c|}{$\mathrm{d}($ IONCs $)=18 \mathrm{~nm}$} & $\mathrm{~d}($ IONCs $)=14 \mathrm{~nm}$ & $d($ IONCs $)=18 \mathrm{~nm}$ \\
\hline IONCS & $110 \pm 9$ & \multicolumn{2}{|c|}{$125 \pm 33$} & $99 \pm 18$ & $120 \pm 12$ \\
\hline CAPS & $239 \pm 21$ & \multicolumn{2}{|c|}{$257 \pm 20$} & $169 \pm 20$ & $215 \pm 20$ \\
\hline WALL & $218 \pm 29$ & \multicolumn{2}{|c|}{$171 \pm 7$} & $136 \pm 14$ & $150 \pm 5$ \\
\hline
\end{tabular}


A

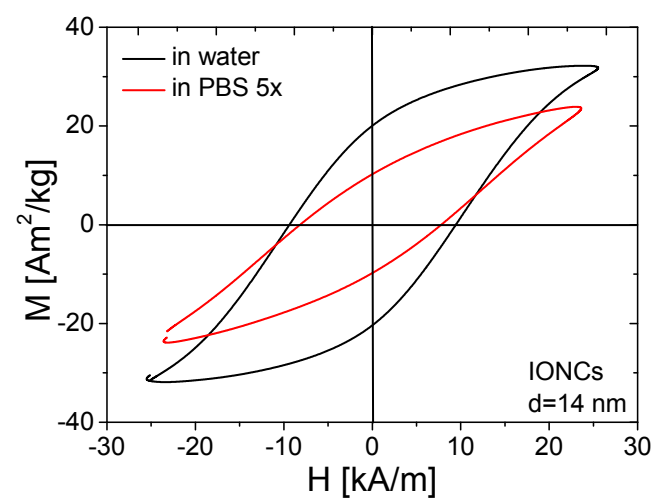

C

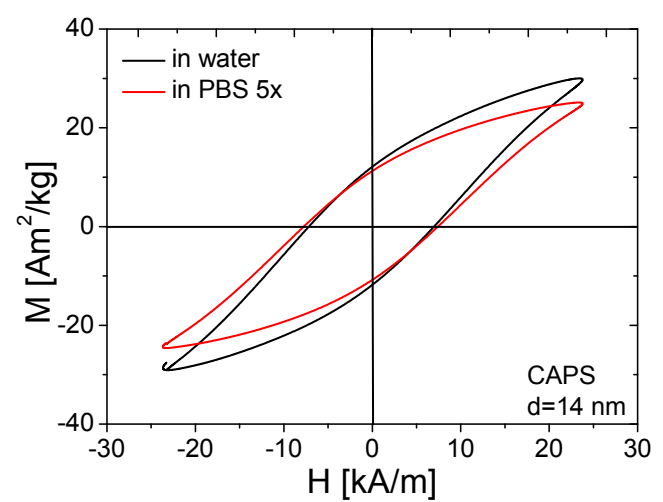

B

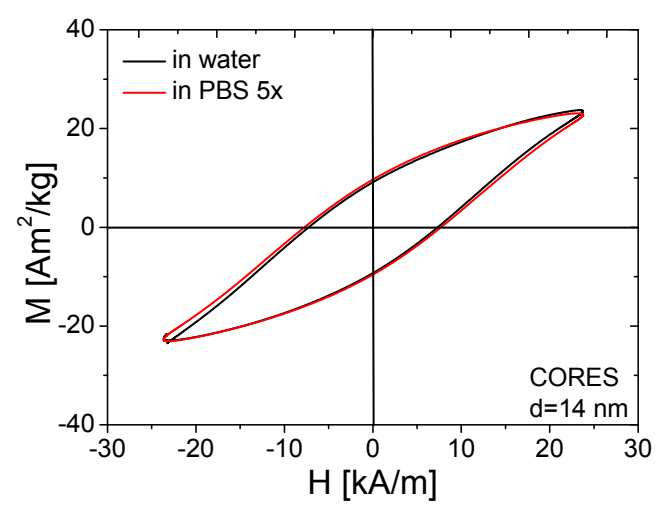

D

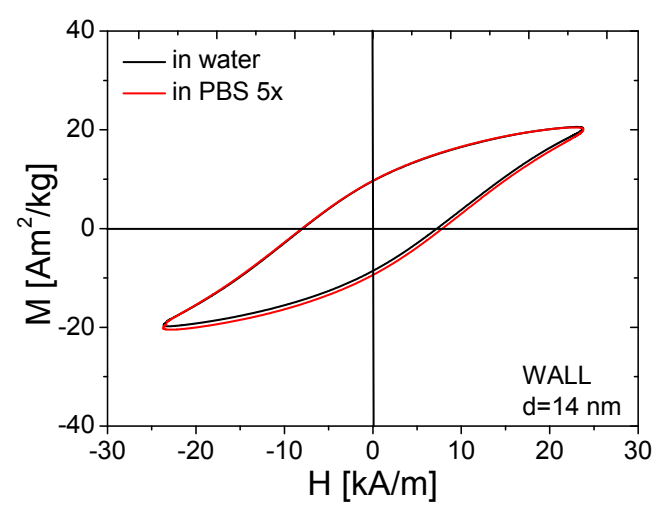

Figure S29: AC hysteresis loops of different magnetic materials dispersed in water (black line) or in PBS $5 x$ (red line). A. free IONCs, B. CaCO 3 cores with embedded $14 \mathrm{~nm}$ IONCS (CORES), C. capsules with $14 \mathrm{~nm}$ IONCS in the cavity (CAPS), D. capsules with $14 \mathrm{~nm}$ IONCs in the wall (WALL). Measurements were performed at 24 $\mathrm{kA} / \mathrm{m}, 100 \mathrm{kHz}, 0.75 \mathrm{~g}(\mathrm{Fe}) / \mathrm{L}$. 
A

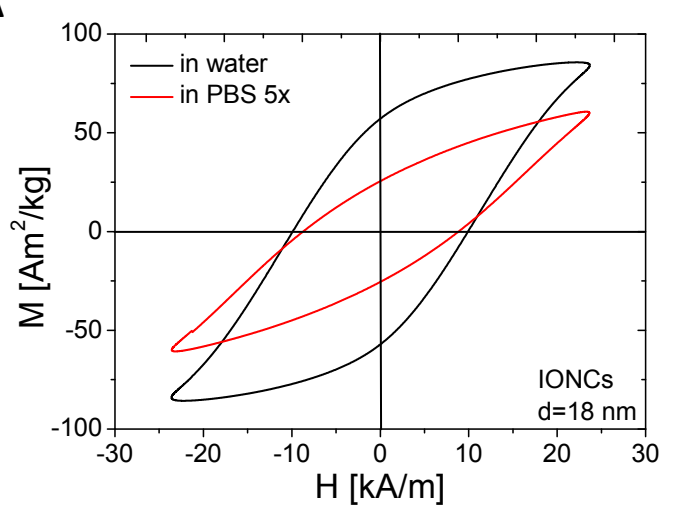

C

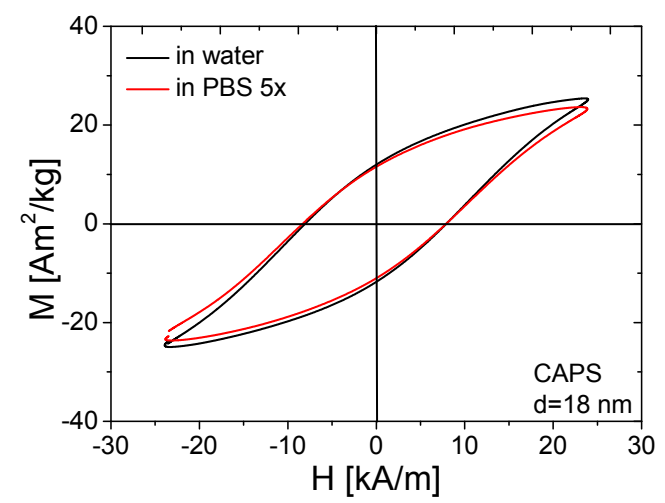

B

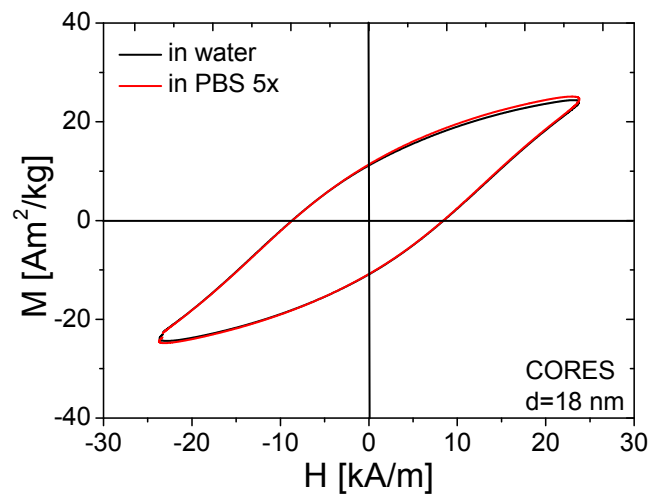

D

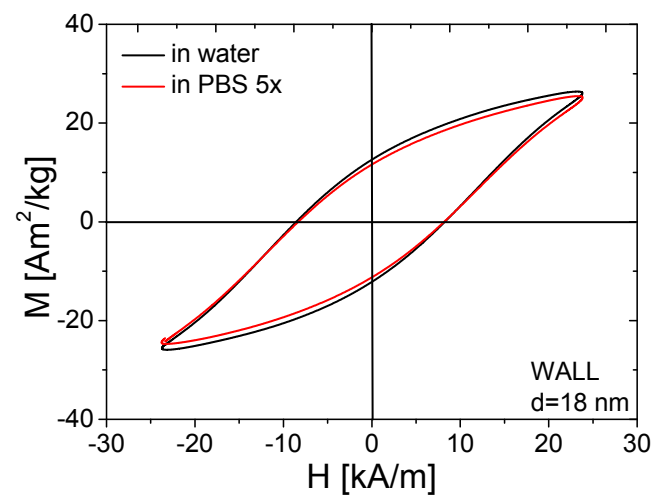

Figure S30: AC hysteresis loops of different magnetic materials dispersed in water (black line) or in PBS 5x (red line). A. free IONCs, B. $\mathrm{CaCO}_{3}$ cores with embedded $18 \mathrm{~nm}$ IONCS (CORES), C. capsules with $18 \mathrm{~nm}$ IONCS in the cavity (CAPS), D. capsules with $18 \mathrm{~nm}$ IONCs in the wall (WALL). Measurements were performed at 24 $\mathrm{kA} / \mathrm{m}, 100 \mathrm{kHz}, 0.75 \mathrm{~g}(\mathrm{Fe}) / \mathrm{L}$. 

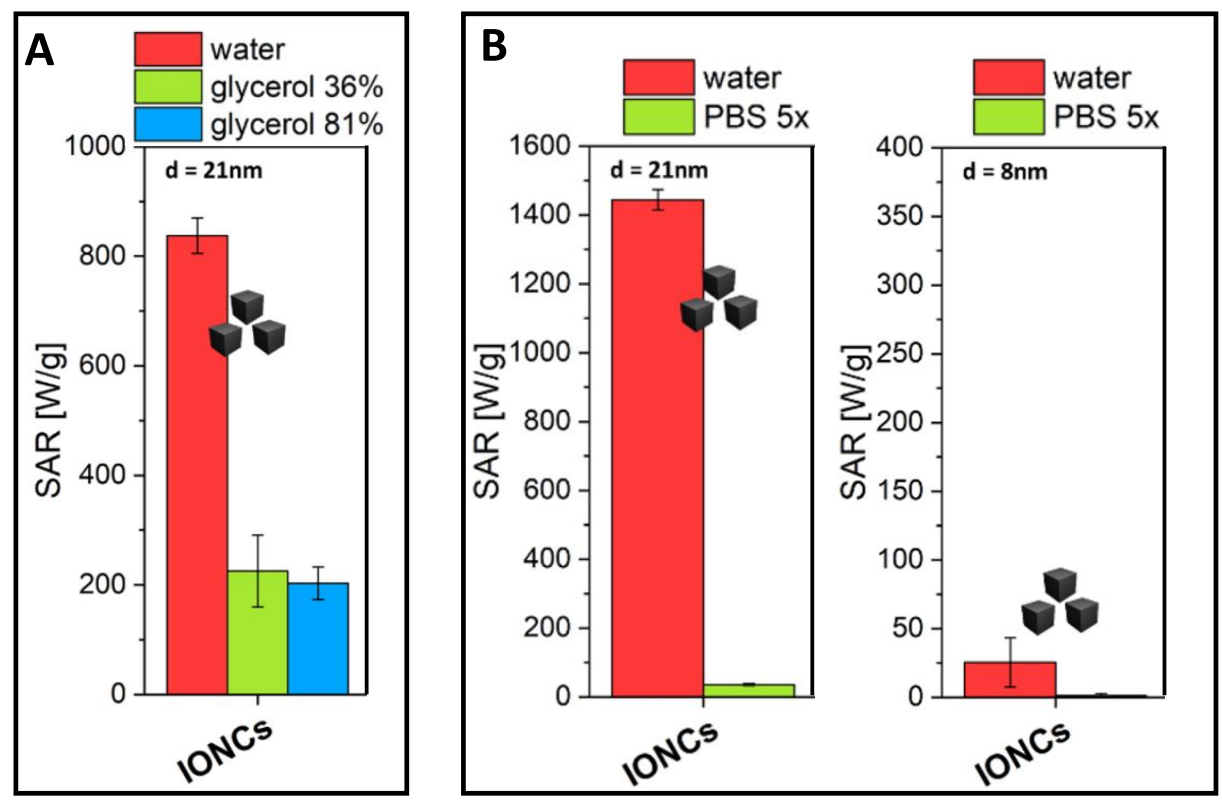

Figure S31: SAR values obtained by A. Calorimetric measurements for free IONCs $(d=21 \mathrm{~nm})$ dispersed in water, glycerol $36 \%$ and glycerol $81 \%$ at $300 \mathrm{kHz}$ and $24 \mathrm{kA} / \mathrm{m}$. B. Magnetometer (areas under hysteresis loops $x$ frequency) for free $21 \mathrm{~nm}$ IONCs (left) and $8 \mathrm{~nm}$ IONCs (right) dispersed in water and PBS $5 x$ measured at $100 \mathrm{kHz}, 24 \mathrm{kA} / \mathrm{m}(30 \mathrm{mT})$.

\section{References}

(1) Gomes, J.; Grunau, A.; Lawrence, A. K.; Eberl, L.; Gademann, K. Bioinspired, Releasable Quorum Sensing Modulators. Chem Commun 2013, 49 (2), 155-157.

(2) Gillich, T.; Acikgöz, C.; Isa, L.; Schlüter, A. D.; Spencer, N. D.; Textor, M. PEG-Stabilized Core-Shell Nanoparticles: Impact of Linear versus Dendritic Polymer Shell Architecture on Colloidal Properties and the Reversibility of Temperature-Induced Aggregation. ACS Nano 2013, 7 (1), 316-329.

(3) Mehdaoui, B.; Carrey, J.; Stadler, M.; Cornejo, A.; Nayral, C.; Delpech, F.; Chaudret, B.; Respaud, M. Influence of a Transverse Static Magnetic Field on the Magnetic Hyperthermia Properties and HighFrequency Hysteresis Loops of Ferromagnetic FeCo Nanoparticles. Appl. Phys. Lett. 2012, 100 (5), 052403. 